\title{
Endogenous indoctrination: Occupational choice, the evolution of beliefs, and the political economy of reform
}

\author{
Gilles Saint-Paul* \\ Toulouse School of Economics \\ Birkbeck College
}

May 5, 2009

\section{Introduction}

Economists usually analyse the political economy of reform in terms of conflicts of interest. They decompose the population in different groups, whose net benefit from the reform differ, and then assume that these groups play some political game -such as majority voting, Downsian competition, probabilistic voting, agenda-setting games, etc - which determines the outcome of the reform.

Yet this approach only tells half the story. In most situations the reform process is assocated with a debate, and the debate is about what the economic effects of the reform are and how the mechanisms underlying those effects work. People disagree not only because their net gains differ but also because they have a different understanding of how the reform works. This aspect is typically neglected in our analysis which assumes that all agents use a single, objective

\footnotetext{
${ }^{*}$ This paper has been prepared for the Economic Journal lecture given at the Royal Economic Society congress, University of Surrey, April 22 2009. I am grateful to John Vickers, John Driffill, Jean-Pierre Florens, and participants to the AFSE meeting, the Namur workshop on political economy, and the Royal Economic Society meeting for helpful comments and suggestions.
} 
model -the correct model of the economy - to compute their gains and losses. If these were true, there would not need to be a debate. But in real-world situations the reform is heavily discussed because there is disagreement on how it will work.

Examples include disagreements between Right and Left on the degree of slack in an economy, the size of the Keynesian multiplier, the distortionary effects of taxation and the location of the economy on a Laffer curve, the longrun effects of the money stock on inflation, ot the ability of private contracting to overcome externalities.

In a country such as France where trade unions and left-wing political parties are still influenced by a Marxist tradition, the debate on unemployment and labour market reform has involved arguments by the unions about whether employment depends on labor costs at all, whether an increase in the minimum wage stimulates the economy because it has a positive effect on consumption, and whether the total level of hours worked is fixed so that only work sharing is capable of creating jobs. This latter "lump-of-labor" fallacy was crucial in the reduction in working time that was implemented in the mid-nineties. While no economist, even in France, believes in the most naive version of the lump-oflabor fallacy, the policy was supported by studies that used Keynesian models where, in the short-run, total hours were determined by aggregate demand, so that working time reduction indeed created jobs upon impact. The fact that many economists put much faith in those models and had far more doubts about how the long-run operates certainly played a role in the unexpectedly high support for the policy among the French economics profession ${ }^{1}$.

That reforms partly rest on the outcome of such debates implies a special role

\footnotetext{
${ }^{1}$ See Saint-Paul (2004) for a discussion.
} 
for one particular class of agents: the intellectuals. These are usually absent from our political economy models, because they assume agents are capable of computing their true net gain by using the true model of the economy. Implicitly, there is a role at best for a class of experts who would elicit that model for the economic agents to use, as opposed to intellectuals who hold heterogeneous views about the world. For this reason, many economists would argue that the intellectual professions are just a veil and that their capacity to influence policy is negligible if agents are truly rational.

Yet in practice a number of authors have pointed out the huge influence of academic ideas on the general public's perceptions and therefore on policy.

In La trahison des clercs (the betrayal of the intellectuals), Julien Benda documents how the ethno-nationalist policies of the early twentieth century were prepared by decades of indoctrination in universities. This should come as a suprise to many contemporary academics who regard themselves as "citzens of the world" , but the ethocentric academics of the nineteenth century were probably as convinced as the contemporary ones of the correctness of their views.

Most notably, Hayek considered that intellectuals had played a crucial role in the spreading and implementation of socialist ideas. Two aspects he emphasised were, first, the existence of a selection bias in occupational choice, and, second, the insulation of intellectuals from reality. The first aspect originates in the fact that the most talented pro-market people quite naturally elected occupations in the business sector, while the most talented anti-market people selected intellectual professions. The second aspect is the result of the fact that by their occupation, intellectuals lack a first-hand experience of the market, which makes them more likely to stick to abstract theories regardless of their empirical relevance. 
In "The intellectuals and socialism", Hayek wrote the following:

In every country that has moved toward socialism, the phase of the development in which socialism becomes a determining influence on politics has been preceded for many years by a period during which socialist ideals governed the thinking of the more active intellectuals.(...) Experience suggests that, once this phase has been reached, it is merely a question of time until the views now held by the intellectuals become the governing force of politics.

(...) Though nobody will regret that education has ceased to be a privilege of the propertied classes, the fact that the propertied classes are no longer the best educated and the fact that the large number of people who owe their position solely to their general education do not possess that experience of the working of the economic system which the administration of property gives, are important for understanding the role of the intellectual. Professor Schumpeter (...) has not unfairly stressed that it is the absence of direct responsibility for practical affairs and the consequent absence of first-hand knowledge of them which distinguishes the typical intellectual from other people who also wield the power of the spoken and written word.

That is, one reason why intellectuals are prone to socialism is their insulation from a real world experience of how markets work. Hayek then describes how the selection bias operates:

(...)for the exceptionally able man who accepts the present order of society, a multitude of other avenues to influence and power are open, while to the disaffected and dissatisfied an intellectual career 
is the most promising path to both infl uence and the power to contribute to the achievement of his ideals.

There is also, according to Hayek, a finer selection bias among the intellectual professions themselves:

Even more than that: the more conservatively inclined man of first class ability will in general choose intellectual work (and the sacrifice in material reward which this choice usually entails) only if he enjoys it for its own sake. He is in consequence more likely to become an expert scholar rather than an intellectual in the specific sense of the word; while to the more radically minded the intellectual pursuit is more often than not a means rather than an end, a path to exactly that kind of wide influence which the professional intellectual exercises. It is therefore probably the fact, not that the more intelligent people are generally socialists, but that a much higher proportion of socialists among the best minds devote themselves to those intellectual pursuits which in modern society give them a decisive influence on public opinion

Finally, he argues in favour of the good faith of such socialist intellectuals:

It is neither selfish interests nor evil intentions but mostly honest convictions and good intentions which determine the intellectuals' views. In fact, it is necessary to recognise that on the whole the typical intellectual is today more likely to be a socialist the more he is guided by good will and intelligence, and that on the plane of purely intellectual argument he will generally be able to make out a 
better case than the majority of his opponents within his class. If we still think him wrong, we must recognise that it may be genuine error which leads the wellmeaning and intelligent people who occupy those key positions in our society to spread views which to us appear a threat to our civilisation. Yet (...) the representatives of the existing order (...) tend to regard the socialist intellectuals as nothing more than a pernicious bunch of highbrow radicals(...)

In this lecture I propose a model where the intellectuals' contribution build an ideological bias in society's learning process about the way the economy works, which is detrimental to the view that the market economy works well. Intellectuals are teachers who are in a privileged situation to influence the prior beliefs of future generations, and they are perfectly sincere; they do not pursue a pre-determined political agenda, and they are not motivated to elect their career by any will to change the world ${ }^{2}$. Nor are their views influenced by any self-serving bias that would rationalize their own economic interests under the banner of the common good. Yet the characteristics of their profession - that it is protected and in the pulic sector - generate a selection bias in the prior beliefs of those who elect to become teachers. That is, one is more likely to choose such a profession, the more unfavorable one's opinion about the market economy. This selection bias is different from the one pointed out by Hayek: People with negative priors against capitalism choose the intellectual profession not out of their own taste, but because they are more likely to rationally believe that the returns from the protected intellectual profession are higher than those from the exposed market activity. In fact, this logic applies to any civil service

\footnotetext{
${ }^{2}$ Related work on the interactions between learning and insitutions include Piketty (1995) and Alesina and La Ferrara (2002).
} 
occupation - and casual evidence suggests that people in those occupations are indeed more likely to hold socialist opinions. But the key point is that the intellectual profession is itself protected and thus prone to that bias.

The model predicts that society will be more left-wing (and lower in learning that the market economy works well, if that is the case),

(i) the greater the weight of the schooling system vs. the family in the formation of beliefs, i.e. the lower the heritability of beliefs, and

(ii) the greater the correlation between one's pessimism about the market economy and the likelihood of becoming a teacher, i.e. the lower the social entropy. In the context of this paper, social entropy refers to how predictable is one's occupation on the basis of one's beliefs.

The existence of such a bias is consistent with casual evidence. Table 1 reports the voting behaviour of French teachers in the 2002 presidential election. The third column gives the teachers' intended vote from a poll published in the magazine Le Monde de l'Education ${ }^{3}$. The fourth column gives the result of the candidate in the first round of the actual election. We see that the candidates from the left and the extreme left got $72 \%$ of the teachers' vote, while these candidates only had $43 \%$ of the total popular vote ${ }^{4}$.

Does this bias have an actual consequence on people's perception? If we believe that French teachers are especially biased, and/or that the school system has an especially high weight in France, then we would expect the French to be particularly averse to the market economy. This is indeed what we observe, as

\footnotetext{
${ }^{3}$ The source for Table 1 is the Sofres polling institute, http://www.tnssofres.com/etudes/pol/280302_enseignants_r.htm

, for column 3, and Yahoo! News,

http://cgi.europe.yahoo.com/fr/profpoli/carte/president1f5.htm,

for column 4.

${ }^{4}$ Some minor candidates were not included in the poll. The $43 \%$ figure includes the leftwing minor candidates and therefore is larger than the sum of the vote for the left in column 4.
} 
can be seen in Table 2. Interestingly, if we compare France with the four other major western European countries in the Table, France has greater expenditures on public education as a fraction of GDP than the others. ${ }^{5}$

Finally, do negative beliefs about the market economy lead people to choose a career in the protected sector? Here again I can only offer tentative evidence, but a recent poll found that $70 \%$ of French youth exiting high school would prefer to work in the public sector ${ }^{6}$. Given that the French hold particulaly negative views about markets, this is at least consistent with my argument. But it could be explained by other phenomena, such as the existence of rents for those who work in the public sector. Such rents are indeed documented.

The idea that beliefs and policies can mutually sustain each other has already been proposed in other contexts. One may in particular mention Piketty (1995), on which Alesina and La Ferrara (2005) and Bénabou and Ok (2001) have elaborated. All these papers examine the link between beliefs in the prospects of social mobility and demand for redistribution. While the policies considered here are different (I focus on employment protection), the main contribution of the present paper is to highlight the role of the intellectual class and how the specificity of their economic situation affects the transmission of beliefs in the rest of society.

I now turn to the setup of the model.

\section{A model of beliefs and occupational choice}

There are overlapping generations of people living two periods. The size of each cohort is normalized to 1 . In the first period of their life, people inherit their prior beliefs from their parents and from the schooling system. At the end of

\footnotetext{
${ }^{5}$ According to the UNDP's Human Development Report (2008), these fractions are France: $5.9 \%$, UK: $5.4 \%$, Italy: $4.7 \%$, Germany: $4.6 \%$, and Spain: $4.3 \%$.

${ }^{6}$ : Source: http://www.ifop.com/europe/sondages/opinionf/jeunesfonctionpubl.asp
} 
that period, they make their occupational choices, electing between a career in teaching, versus a competitive labor market. During the second period, they work and produce children. Then they transmit their beliefs to their children.

The utility function is given by

$$
V=E(w)-e,
$$

where $w$ is the wage, $E$ the expectations operation, and $e$ a disutility parameter associated with being in a particular sector.

If people work in the market, they are paid their constant marginal productivity $\bar{w}$. However, participation in the market is associated with labor market risk. Each individual is exposed to such risk through $k$ independent draws. For each draw, with probability $s$, the worker is unsuccessful, i.e. unemployed, earning a zero wage. With probability $1-s$, the individual is employed and earns $\bar{w}$. We assume that the disutility of being in the market sector is the same for all agents and normalize it to zero. This is without loss of generality as only the difference between the two sectors matters.

Thus the (true) expected utility of the worker is

$$
V=(1-s) \bar{w} .
$$

Labor market experience is uncorrelated across agents and across time.

Thus, the parameter that people learn is the probability of being employed, and people learn it from their own experience. This assumption is clearly subject to the criticism that there are other ways of learning this probability than through one's own experience. People could learn the true value of $s$ by pooling information on their objective labor market trajectories, say through some statistical agency. But the model is essentially unchanged if instead $s$ is interpreted as any variable that affects the subjective utility from working in the market vs. 
the non-market activity. Clearly, many of these dimensions are difficult to measure objectively. Also, it has been pointed out by psychologists and behavioural economists that people have greater confidence in their own experience than in objective information, a form of cognitive dissonance called the "availability bias".

People who work in the public sector earn a wage $\omega$ and experience no labor market shock. Thus their utility is

$$
V=\omega-e_{T}
$$

Upon making their occupational choice, workers have a prior belief on the value of $s . s$ can only take two values, $s_{H}$ and $s_{L}<s_{H}$. If $s=s_{H}$ we will say that the market economy is 'bad', otherwise that it is 'good'. Thus, the prior belief is defined as the probability $p$ that $s=s_{H}$. At each date $t$ there is a distribution of $p$ in the population, which reflects the different labor market histories of their ancestors. We can represent that by a function $p_{t}(i)$, where $i \in[0,1]$ indexes a particular individual in the generation that is working at $t$.

An exogenous total fraction $n$ of the working cohort will become teachers. This parameter captures the inverse of the productivity of the educational system, relative to the rest of the economy. Their wages are financed by a uniform lump-sum tax over the working population.

The disutility $e_{M}$ is drawn from an exogenous distribution with c.d.f. $\phi($.$) .$ These shocks are uncorrelated between individuals, regardless of the generations they belong to and regardless of their biological links - thus one cannot inherit one's parent taste for the teaching occupation.

A worker will prefer to be a teacher rather than work in the private sector if and only if

$$
e_{M}<\Delta(p, \omega),
$$


where

$$
\Delta(p, \omega)=\omega-\left[p\left(1-s_{H}\right)+(1-p)\left(1-s_{L}\right)\right] \bar{w}
$$

is the expected income difference between a public and a private worker.

Therefore, the proportion of workers who want to become teachers and have a prior $p$ is equal to $\phi(\Delta(p, \omega))$. This relationship can be aggregated to obtain the 'supply curve' of teachers as a function of $\omega$ :

$$
S_{T}(\omega, t)=\int_{0}^{1} \phi\left(\Delta\left(p_{t}(i), \omega\right)\right) d i .
$$

In equilibrium, the government adjusts the wage it offers to teachers in such a way that exactly $n$ people are willing to work in the profession; thus supply equals demand:

$$
S_{T}(\omega, t)=n .
$$

We parametrize $G()$ in order to control the precision of the mapping from beliefs to occupational choice as a varying parameter. Thus we assume the following functional form:

$$
\phi(\Delta)=\frac{e^{\Delta / \sigma}}{1+e^{\Delta / \sigma}} .
$$

The parameter $\sigma$, which we call social entropy, tells us how predictable one's occupation is as a function of one's prior beliefs. If it is low, then such predictability is high: for $\Delta$ not too different from zero $\phi(\Delta)$ will the be close to zero or one. The distribuition of tastes for the teaching occupation is close to a mass point and typically all workers with a sufficiently pessimistic belief about the market economy will become teachers, while the others will work in the private sector. By contrast, for $\sigma$ large the distribution of tastes is smooth 
and the proportion of teachers among agents with certain beliefs is insensitive to those beliefs.

We now describe the intergenerational transmission of beliefs. The priors of a new generation are shaped by those of their teachers and their parents. Consider a young individual. Call $q$ his parent's posterior probability that $s=s_{H}$. Let $q_{T}$ the random variable representing the posterior beliefs in the population of teachers. Then the child's prior $p^{\prime}$ is such that:

$$
\ln \frac{p^{\prime}}{1-p^{\prime}}=\theta \ln \frac{q}{1-q}+(1-\theta) E\left(\ln \frac{q_{T}}{1-q_{T}}\right)
$$

Thus it is (up to a logistic transformation, used for convenience) a linear combination of the family's and the teacher's priors. The latter intervene through an aggregate, which captures the idea that while the family is unique, people are exposed to a variety of teachers throughout their upbringing; thus the contribution of the school system is the same for all individuals ${ }^{7}$. We will refer to $\theta$, the weight of the family, as the heritability parameter.

Beliefs are updated in a Bayesian fashion on the basis of one's labor market experience. As teachers do not work on the private sector, they get no draw and therefore do not update their prior. Therefore for any teacher with prior $p$, his posterior is $q=p$. In the private sector, Bayes law implies that the posterior of a worker with prior $p$ who did not get a job is

$$
\tilde{p}=\frac{s_{H} p}{p s_{H}+(1-p) s_{L}}
$$

while if he did get a job the posterior is

$$
\tilde{p}=\frac{\left(1-s_{H}\right) p}{p\left(1-s_{H}\right)+p\left(1-s_{L}\right)} .
$$

\footnotetext{
${ }^{7}$ Alternatively, we could assume pupils are exposed to a finite number of teachers and there would be some randomness in the contribution of the school system to prior beliefs. This would merely complicate the analysis without affecting its essence.
} 
This rule is applied for each of the $k$ market draws that people are subjected to. Using the convenient logistic transformation we see that the final posterior $q$ is determined by

$$
\ln \frac{q}{1-q}=\ln \frac{p}{1-p}+X_{k},
$$

where $X_{k}$ is the sum of $k$ independent draws from a binomial distribution, equal to $\ln \frac{s_{H}}{s_{L}}>0$ with probability $s$ and $\ln \frac{1-s_{H}}{1-s_{L}}<0$ with probability $1-s$. Note that $E\left(X_{k}\right)=k\left(s \ln \frac{s_{H}}{s_{L}}+(1-s) \ln \frac{1-s_{H}}{1-s_{L}}\right)=k z(s)$. Furthermore, $z\left(s_{L}\right)<$ $0<z\left(s_{H}\right)$. Consequently, if dynasties were left on their own with no interference from the school system $(\theta=1)$, priors would converge to the correct ones: in expectations, the $\log$ odds ratio $\ln \frac{p}{1-p}$ would fall by a constant negative amount each period if $s=s_{L}$ and therefore $p$ would converge to zero. Thus we have the following benchmark result:

Proposition 1 - Assume $\theta=1$ and $s=s_{L}$. Then for any $\varepsilon>0, \lim _{t \rightarrow+\infty} P(p>$ $\varepsilon)=0$.

Proof - This is a standard result, see e.g. Chamley (2000). Let us however provide a quick proof. Given the distribution of $p$, next generation's priors $p^{\prime}$ are equal to the preceding generation's posterior $q$. Thus $E \ln \frac{p^{\prime}}{1-p^{\prime}}=$ $E \ln \frac{p}{1-p}+k z\left(s_{L}\right)$, implying that at date $t E_{t} \ln \frac{p}{1-p}=E_{0}+t k z\left(s_{L}\right)$. Therefore, $\lim E \ln \frac{p}{1-p}=-\infty$.

Next, since the draws of $X_{k}$ are independent of the individuals' initial $p$, we have $\operatorname{Var}\left(\ln \frac{p^{\prime}}{1-p^{\prime}}\right)=\operatorname{Var}\left(\ln \frac{p}{1-p}\right)+\operatorname{Var}\left(X_{k}\right)$. Thus at any date $t \operatorname{Var}_{t}\left(\ln \frac{p}{1-p}\right)=$ $V_{0}+t \operatorname{Var}\left(X_{k}\right)$. By Chebyshev's inequality, for any $\alpha \in \mathbb{R} P\left(\ln \frac{p}{1-p}>\alpha\right) \leq$ $\frac{V_{0}+t \operatorname{Var}\left(X_{k}\right)}{\left(\alpha-E_{0}-t k z\left(s_{L}\right)\right)^{2}} \rightarrow 0$. A change of variable gives the text's statement.

Q.E.D. 


\section{Do beliefs converge?}

I now discuss the economy's ability to learn the true parameter $s$ when the learning process is perturbated by the school system. In the rest of the discussion I assume $s=s_{L}$ (the market economy is "good"), which is the case of interest since the teacher bias then hampers learning.

In the model, the existence of the school system affects the formation of beliefs through three main mechanisms, which I discuss in turn.

\subsection{Mechanism \#1: The self-selection effect}

The most important mechanism is the bias generated by the self-selection of relatively pessimistic people into the teaching profession. If, at the end of any date $t$, the distribution of prior beliefs among the young generation is given by a density $f_{t}(p)$, then beliefs among the teaching profession are distributed with density $\psi_{t}(p) f_{t}(p)$, with

$$
\psi_{t}(p)=\frac{\phi\left(\Delta\left(p, \omega_{t}\right)\right)}{n}
$$

Given that $\phi()$ is increasing, $E \ln \frac{p_{T}}{1-p_{T}}>E \ln \frac{p}{1-p}$; since $q=p$ for teachers, this means that the school component in (3) contributes to an upward drift in priors: people tend to become more pessimistic over time because children of dynasties who had bad draws are more likely to elect the teaching profession.

Assuming the market economy is good $\left(s=s_{L}\right)$, can the influence of the school system invalidate Proposition 1 and prevent the population from learning the true value of $s ?^{8}$ Clearly, it depends on whether the contribution to learning of the family's market experience has a stronger effect than the teacher bias. Intuitively, this is more likely to be the case, the greater the level of heritability $\theta$, and the smaller the teacher bias. The latter is larger, the smaller social entropy,

\footnotetext{
${ }^{8}$ If the market economy is bad, teacher bias makes beliefs converge faster to the truth.
} 
since selection of teachers amongst the most pessimistic groups is stronger when $\sigma$ is low.

The following proposition validates this intuition. It tells us that convergence still holds provided $\theta$ and $\sigma$ are not too small.

PROPOSITION 2 - There exists a critical value of $\theta, \theta_{m}(\sigma, k)$, such that:

(i) $0 \leq \theta_{m}(\sigma, k)<1$ and $\theta_{m}(\sigma, k)$ is decreasing in both $\sigma$ and $k$ unless $\theta_{m}(\sigma, k)=0$.

(ii) If $\theta>\theta_{m}(\sigma, k)$ then $\lim _{t \rightarrow+\infty} P(p>\varepsilon)=0$.

(iii) For any $k, \exists \sigma^{+}(k), \forall \sigma>\sigma^{+}(k), \theta_{m}(\sigma, k)=0$.

Proof - See Appendix for details. The proof involves using Schwarz's inequality to put an upper bound on the difference between the teacher's average beliefs and those of the rest of the population. One can then show that if $\theta, \sigma$ and $k$ are large $\ln \frac{p}{1-p}$ goes to $-\infty$ in expectations because that upper bound is dominated by the contribution of the expected value of $X_{k}$ in the "private" part of the next generation's belief. Finally, one uses Chebychev's inequality to get convergence in probability out of convergence in expectations.

Thus, if there is enough social entropy and if the weight of the family in the transmission of beliefs is large enough, then the teacher bias does not prevent society from eventually learning the true value of $s$ if $s=s_{L}$ (of course learning is facilitated by the teacher bias if $s=s_{H}$ ).

On the other hand, can erroneous beliefs persist if entropy and heritability are small? To answer this question I resort to numerical simulations. I simulate an economy with 1000 agents, who start from random beliefs that are uniformly distributed between 0 and 1-implying that the initial average belief is equal to $p=0.5$. At each date, a random disutility of teaching is drawn for each 
individual; then the equilibrium wage and the average value of $\ln \frac{q_{T}}{1-q_{T}}$. The beliefs of the next generation are then computed and the model is iterated.

What do we find?

Figure 1 represents the evolution of the' mean belief $p$ along with its 2standard deviation band, for various values of $\sigma$ and $\theta$. In all those simulations, the average $p$ eventually falls with time: The teacher bias does not seem to prevent society from learning the true value of the parameter $s$ in the long run. Thus, these simulations suggest convergence is more general than implied in Proposition 2.

However, for low values of $\theta$ and $\sigma$, convergence is quite slow as the average $p$ can sharply increase as an outcome of the teacher bias. Thus, for $\sigma=0.05$ and $\theta=0.1$, after 100 periods the average $p$ is still above 0.6. By contrast, in figures $1 \mathrm{e}, 1 \mathrm{f}$, and $1 \mathrm{~g}$, convergence is almost complete after 100 periods, either because a high social entropy generates a small teacher bias (Figure 1e), or because the school system has a small weight in the transmission of belief (Figure 1f), or both (Figure 1g). We also note that in the short run the standard deviation is smaller, the larger the role of the school. This is not surprising, since the teacher's contribution to the beliefs is the same for all agents by assumption. In the long-run, though, the labor market experience of people working in the private sector is a powerful force for reducing the variance of beliefs, which is almost zero after 100 periods in figure $1 \mathrm{~g}$ despite the large weight of the family.

Figures 2 and 3 isolate the effect of the family and social entropy on the speed of convergence.

In the extreme case where there is no social entropy, i.e. when the $n$ teachers are identical to the $n$ most pessimistic members of society, convergence no longer holds. Instead, the mean belief converges to $p=1$. This is easy to understand. 
At each generation, the $n$ children of teachers inherit a mean odds ratio which is exactly equal to that of the teachers. Consequently, the $n$ most pessimistic agents (the teachers of the next generation) will have an average odds ratio which is even higher than that. Because teachers are insulated from market draws, their children on average are equally pessimistic, so that the average belief of teachers can only deteriorate (i.e. $p$ goes up) over time. On average, those who become teachers despite that their parents weren't will earn a slot in that profession only because they typically are even more pessimistic - their dynasty got an abnormally bad sequence of draws. But as long as a dynasty has joined the teaching profession, they get no draw at all; hence there is no countervailng phenomenon.

We can indeed prove formally:

PROPOSITION 3 - Assume $\sigma=0$. Then $\lim _{t \rightarrow+\infty} P(p<1-\varepsilon)=0$.

Proof - See Appendix. The idea is first to show that the most optimistic teacher's belief (defined as $\ln \frac{p}{1-p}$ ) follows an increasing sequence, due to the insulation of teachers. Then one can show that it cannot converge to a finite limit. Otherwise, the expected teacher belief would also have a finite limit, since it contributes with weight $1-\theta$ to the most optimistic teacher's belief. But one can always find a positive mass of "market" dynasties that have sufficiently adverse shocks so as to eventually become teachers and increase their mean belief by a first order amount, thus pushing it above any finite limit. Thus $\ln \frac{p}{1-p}$ must go to infinity for the teachers and this must also be true for the rest of the population, by virtue of (3).

Figure 4 shows some simulations for $\sigma=0$. Interestingly, while a higher weight of the family slows convergence to $p=1$ at the beginning of the learning process, it eventually speeds it, albeit slightly. This is because a dynasty which 
has had a series of bad draws in the market - bad enough to make it more pessimistic than the average teacher - is more pessimistic, the greater the weight of the family; hence the contribution to the teacher bias of the member of this dynasty who joins the teaching profession is larger.

\subsection{Mechanism \#2: The Insulation effect}

The selection of teachers is the main determinant of the speed of learning, but there are other ones. The second mechanism reinforces the selection effect; it comes from the fact that the teachers do not get a draw from being confronted with the market, which prevents their children from learning. Consider the extreme case where social entropy is nil. Then in each generation, the $n$ most pessimistic people will become teachers. Their children's priors, in turn, will be (up to a monotonic transformation) a weighted average of the average prior of the teachers and of their own parents'. Since their parents are also teachers, in terms of priors the $n$ children of the teachers are also the $n$ most pessimistic ones. If they were to become teachers, their beliefs would eventually converge to the initial average of the $n$ most pessimistic people, ruling out any convergence of beliefs to the true value of $s$ in the population at large (even in the case where $\theta=1$ there would be a positive masse of teachers' children who do not learn the correct value of $s$ ). Whatever occupational mobility occurs when $\sigma=0$ further aggravates this problem: Those who become teachers despite that their parents were not must inherit a history of labor market experiences which is so negative that they are more pessimistic than the marginal teacher; therefore these individuals further contribute to making the teaching profession more pessimistic-hence Proposition 3.

Thus the insulation effect slows convergence of learning, but for $\sigma>0$ its magnitude is small compared to the selection bias of beliefs. As an illustration, 
Figure 5 reports the evolution of the average belief $p$ for $\sigma=0.1$ and $\theta=0.4$, in the standard model and in one version of the model where the insulation effect has been neutralized by allowing teachers to get draws from the market in the same fashion as workers in the private sector. We see that after 100 periods the econmy without insulation has an average belief which is just 0.03 lower than under insulation.

\subsection{Mechanism \#3: The social learning effect}

The third mechanism that comes into play has little impact on the average belief but affects the dispersion of beliefs. Ignoring biases, exposure to a teacher smooths learning by indexing priors on the beliefs of more than one adult. Since equation (3) is linear, this does not affect the speed of convergence as measured by the evolution of $E \ln \frac{p^{\prime}}{1-p^{\prime}}$. However, since the teacher's contribution is equal to the population average, the variance of beliefs is smaller, the smaller $\theta$. By Chebyshev's inequality, we can then impose a stricter upper bound on the fraction of people whose beliefs are more pessimistic than some cutoff value $p^{*}$, the smaller $\theta$. But this has very little impact on the evolution of average beliefs and is dwarfed by the insulation effect. However it probably explains why a marginally more pessimistic average belief sometimes arises as a result of an increase in $\theta$, although in addition to being quite small that effect is also short-lived.

\section{Economic determinants of the bias}

The preceding discussion has emphasized the "sociological" determinants of the bias, i.e. the weight of the family and social entropy. The model also predicts that the bias has economic determinants. They come into play through the 
following mechanism: We have seen that the teacher bias comes from the fact that the perceived gain from being a teacher, $\Delta$, increases with $p$. Equation (1) further reveals that the sensitivity of $\Delta$ with respect to $p$ depends on the parameters of the economy, in particular $s_{H}, s_{L}$, and $\bar{w}$. That is, a change in the economic environment will, in expectation, affect the welfare of optimistic people differently from that of pessimistic ones, and this will have an impact on the degree to which pessimistic people are more represented in the teaching profession. Another, more subtle effect, comes from the fact that the function $\phi()$ is non linear. However, I will neglect that effect in the discussion below.

To analyze these issues, we can define the teacher bias at any point in time as

$$
\begin{aligned}
B_{t} & =E p_{T t}-E p_{t} \\
& =\int_{0}^{1} p\left(\frac{1}{n} \phi(p, \omega, \lambda)-1\right) f_{t}(p) \mathrm{d} p
\end{aligned}
$$

where for convenience $\phi()$ has been rewritten as a function of $p, \omega$, and any parameter of interest $\lambda$. A parameter change has a direct effect on $B_{t}$ and an indirect one through its induced shift in $\omega$. The latter can be computed differentiating (2):

$$
d \omega=-\frac{E\left(\frac{\partial \phi}{\partial \lambda}\right)}{E\left(\frac{\partial \phi}{\partial \omega}\right)} d \lambda,
$$

where all expectation notations now refer to an integral weighted by $f_{t}()$.

Differentiating (4) and using (5) we get that

$$
\begin{aligned}
d B= & \frac{1}{n} \mathrm{~d} \lambda\left[E\left(p \frac{\partial \phi}{\partial \lambda}\right)-E(p) E\left(\frac{\partial \phi}{\partial \lambda}\right)\right] \\
& +\frac{1}{n} E\left(\frac{\partial \phi}{\partial \lambda}\right)\left[E(p)-\frac{E\left(p \frac{\partial \phi}{\partial \omega}\right)}{E\left(\frac{\partial \phi}{\partial \omega}\right)}\right] .
\end{aligned}
$$

The first term in brackets will be positive (resp. negative) for any parameter 
shift such that $\frac{\partial^{2} \phi}{\partial \lambda \partial p}>0$ (resp. $\left.<0\right)$. Since $\partial \phi / \partial \lambda=\phi^{\prime}(\Delta) \partial \Delta / \partial \lambda$, this will be true if $\partial^{2} \Delta / \partial \lambda \partial p>0$ as long as we neglect the effects from the nonlinearity of $\phi()$. This approximmation would also lead us to neglect the second term in brackets, since $\frac{\partial \phi}{\partial \omega}=\phi^{\prime}(\Delta)$.

Thus we expect the bias to go up for any parameter shift such that $\partial^{2} \Delta / \partial \lambda \partial p>$ 0. In particular, we have that

$$
\frac{\partial^{2} \Delta}{\partial \bar{w} \partial p}=s_{H}-s_{L}>0 .
$$

A more productive economy will have more biased teachers. This is because the more pessimistic people expect to be employed less often, therefore their welfare increases by less, when wages in the market goes up, than for the optimistic ones. The model consequently predicts a stronger teacher bias in more affluent economies. This insight is confirmed by numerical simulations. Figure 6 reports one of them for $\theta=0.2$ and $\sigma=0.1$, where we compare the evolution of average beliefs for $\bar{w}=1$ vs. $\bar{w}=1.2$. In the latter case, people are more pessimistic, due to stronger selection of teachers, by a moderate 0.03 .

It is also of interest to study the effect of $n$, the number of teachers, on the bias. Differentiation of (2) now yields

$$
d n=E\left(\frac{\partial \phi}{\partial \omega}\right) d \omega
$$

Substituting this into the differentiation of (4) yields

$$
d B=\frac{d n}{n}\left(\frac{E\left(p \frac{\partial \phi}{\partial \omega}\right)}{E\left(\frac{\partial \phi}{\partial \omega}\right)}-\frac{E(p \phi)}{E(\phi)}\right) .
$$

If we again neglect the effect of the nonlinearity in $\phi$, we have that $d B / d n<0$ since $\phi^{\prime}>0$, which implies that $E(p \phi)>E(\phi) E(p)$. When there are more teachers, the bias is falling. This is intuitive since their recruitment has to be more diversified. 


\section{Political economy consequences}

So far, we have discussed a pure learning process in a context where no actual policy is taking place. In this section I provide an example where the beliefs have an influence on policy, and where there is a reverse feedback effect of policy on beliefs.

The story is simple: if people distrust the market economy they are likely to support "rigid" policies that reduce exposure to the market. The kind of policies that I have in mind are employment protection. By reducing the job loss rate of insiders, employment protection reduces the number of jobs people hold over their career, which in turn implies that they get fewer "draws" about the working of the market economy. Formally, it means that $k$ falls.

This reduced exposure will in turn provide people with fewer opportunities to learn, thus slowing the convergence process for beliefs. In the presence of teacher bias, this makes it more likely that pessimistic beliefs persist. Analytically, this means that the value of $k$ is lower, so that the conditions for convergence established in Proposition 2 are less likely to be satisfied. This in turn reinforces the support for rigidity in the future. Thus a vicious circle arises where, because people hold few jobs, their posteriors do not move sufficiently quickly to compensate for the biases transmitted to the next generation by the school system. That generation will then be overly pessimistic and support policies that protect their jobs, implying they will also learn little from their labor market experience.

How can this story be embodied into the model? I assume a simple voting process every period. At the beginning of any period $t$, the adult population who is allocated to the market sector gets its first draw. Consequently, a fraction $1-s$ of them gets jobs and the remainder is unemployed. Immediately, after, 
they vote on a labor market policy which allows them to trade job security for wages. Building on Saint-Paul (1993, 2000), I assume that they face a trade-off represented by a function $\bar{w}=h(k), h^{\prime}>0$, which tells us that productivity and therefore wages are higher, the more flexible the economy, i.e. the greater $k$. Each draw contributes to a fraction $1 / k$ of average income during the period. Hence, the expected utility of an employed worker, conditional on $s$, is given by

$$
\begin{aligned}
U_{e}(s, k) & =\frac{1}{k} h(k)+\left(1-\frac{1}{k}\right)(1-s) h(k) \\
& =h(k)\left[1-s \frac{k-1}{k}\right] .
\end{aligned}
$$

This expression reflects the fact that the worker already has a job and that a reduction in $k$ increases the relative weight of his current job - i.e. the expected duration of that job - which reduces the fraction of time spent in unemployment. Thus the employed are more in favor of employment protection than under a veil of ignorance. In that case their expected utility would simply be $h(k)(1-s)$, and they would support the highest possible value of $k$.

The unemployed's expected utility is equal to

$$
U_{u}(s, k)=\left(1-\frac{1}{k}\right)(1-s) h(k) .
$$

Clearly, they should support employment protection even less than under a veil of ignorance. Note though that this increased right-wingness of the unemployed as compared to the employed only relates to employment protection and is only due to their current labor market situation. The model predicts that bad draws makes people more skeptical about the market economy. Hence even though the unemployed oppose employment protection, they are generally more likely to subscribe to ideologies that reject the market economy.

As for teachers, they are clearly indifferent with respect to the value of $k$. Consequently, I assume for simplicity that they do not vote. 
For an employed agent with belief $p$, expected utility is then simply equal to

$$
\begin{aligned}
V_{e}(k, p) & =p U_{e}\left(s_{H}, k\right)+(1-p) U_{e}\left(s_{L}, k\right) \\
& =h(k)\left[1-\left(p s_{H}+(1-p) s_{L}\right) \frac{k-1}{k}\right] .
\end{aligned}
$$

Clearly, $\frac{\partial^{2} V_{e}}{\partial k \partial p}=-\left(h^{\prime}(k) \frac{k-1}{k}+\frac{h(k)}{k^{2}}\right)\left(s_{H}-s_{L}\right)<0$. Therefore, the employed's preferred value of $k$ is a weakly decreasing function of $p .{ }^{9}$ This cross-derivative property also implies that preferences are single-crossed. Therefore, we can prove the following:

PROPOSITION 4 - Assume that at any date $t$ there is majority voting among the adult population on the value of $k$. Then there exists a majority winner given by $k^{*}=\arg \max V_{e}\left(k, p_{D}\right)$, where $p_{D}$ is the decisive voter's belief defined by

$$
s+(1-s) F_{t}\left(p_{D}\right)=1 / 2 .
$$

If $F_{t}$ is replaced by another distribution which dominates it in the first-order sense, then $p_{D}$ goes up and $k$ cannot fall.

PROOF - Consider a candidate deviation $k^{\prime}>k^{*}$. Let $p \geq p_{D}$. Then

$$
\begin{aligned}
V_{e}\left(p, k^{\prime}\right) & =V_{e}\left(p_{D}, k^{\prime}\right)+\int_{p_{D}}^{p} \frac{\partial V_{e}}{\partial p}\left(q, k^{\prime}\right) d q \\
& =V_{e}\left(p_{D}, k^{\prime}\right)+V_{e}\left(p, k^{*}\right)-V_{e}\left(p_{D}, k^{*}\right)+\int_{p_{D}}^{p} \int_{k^{*}}^{k^{\prime}} \frac{\partial^{2} V_{e}}{\partial p \partial k}(q, m) d q d m \\
& \leq V_{e}\left(p, k^{*}\right),
\end{aligned}
$$

since $V_{e}\left(p_{D}, k^{\prime}\right) \leq V_{e}\left(p_{D}, k^{*}\right)$ and $\frac{\partial^{2} V_{e}}{\partial p \partial k}(q, m)<0$. Thus, a fraction of at least $(1-s)\left(1-F_{t}\left(p_{D}\right)\right)=1 / 2$ people prefer $p_{D}$. A similar reasoning holds for $k^{\prime}<k^{*}$,

\footnotetext{
${ }^{9}$ This follows from a simple supermodularity argument and therefore is true despite that $k$ must be integer and thus does not satisfy first-order conditions. See Milgrom and Roberts (1990).
} 
taking into account the fact that the fraction $s$ of unemployed workers now oppose the alternative, in addition to the employed such that $p \leq p_{D}$. Finally, the second part of the proposition derives directly from (7). QED

The second part of Proposition 4 tells us that there is a sense in which greater pessimism breeds more rigid institutions ${ }^{10}$.

As a simple illustration, take the case where one can only elect between $k=1$, in which case the wage is $h(1)=w_{1}$, and $k=2$, in which case the wage is $h(2)=w_{2}>w_{1}$. By (6) an employed voter favors the more rigid institution if and only if

$$
w_{1}>w_{2}\left[1-\frac{p s_{H}+(1-p) s_{L}}{2}\right] .
$$

This defines a critical value of $p, p^{*}$, such that all the employed more pessimistic than $p^{*}$ support rigidity. The latter formula gives

$$
p^{*}=\frac{2\left(\frac{w_{2}-w_{1}}{w_{2}}\right)-s_{L}}{s_{H}-s_{L}}
$$

For example, if employment protection reduces wages by $5 \%$ and the rigid economy has a job loss rate of $5 \%$ compared to $15 \%$ in the flexible one, we get $p^{*}=0.5$.

The effect of beliefs on the support for employment protection has some interesting implications.

First, it tends to widen the gap between the speed of learning of a pessimistic society and that of an optimistic one, regardless of the cause of such a discrepancy. We already know, for example, that for a given $k$ a society with a low $\theta$ is more pessimistic and learns more slowly (if $s=s_{L}$ ) than if $\theta$ is high.

\footnotetext{
${ }^{10}$ However, our setting does not obviously imply that, say, a lower value of $\sigma$ or $\theta$ increases pessimism in the precise sense of first-order stochastic dominance. This is also true when we want to analyze how the teacher bias at date $t$ may foster future increases in rigidity. Second, in general equilibrium the relevant distribution of beliefs for the vote depends on the distribution of teachers, which itself depends on the expected market wage and therefore on the expected outcome of the vote.
} 
This difference would be magnified if in addition the pessimistic society were to choose rigid institutions, say $k=1$, and the optimistic one chose flexible ones, e.g. $k=2$.

Second, it provides (to some extent) a mechanism for political hysteresis. By this I refer to the fact that transitory aggregate shocks may have lasting effects because they are associated with a change in institutions through their impact on the size of their constituency. Here, if people hold more pessimistic beliefs about $s$ after a recession, they are more likely to support a low value of $k$, which in turn will lead to lower productivity and a greater unemployment duration. Of course, if people understand the transient nature of the recession, it is not rational for them to alter their beliefs about $s$. But one can envisage a model where changes in job security may result from either temporary aggregate shocks or long-lasting structural shifts of $s$ between $s_{L}$ and $s_{H}$, and where these two sources are not distinguishable by the agents. In such a case adverse transitory shocks will indeed induce Bayesian learners to increase $p$.

Figure 7 illustrates this discussion by comparing two economies that have the same structural parameters $\sigma=0.05$ and $\theta=0.2$ but differ in their initial beliefs (i.e. an initial uniform distribution around $p=0.4$ vs. $p=0.5$ with the same spread equal to 0.8 ). The kinks in each curve indicate a political transition from $k=1$ to $k=2$, which is associated by an acceleration of the learning process. We see that the transition take place at a later date in the society which is initially more pessimistic. Furthermore, the two societies' beliefs diverge during the period when their labor market institutions differ. In the long run, though, the forces for convergence prevail and both economies end up with $k=2$ and a convergence toward $p=0$. 


\section{Conclusion}

We have analysed a model where beliefs and institutions coevolve as a result of individual families' own market experience but also of the contribution of a specific class of agents: "the intellectuals". While they do not pursue any conscious ideological or political goal, and elect their profession on the basis of a pure cost/benefit analysis, they nevertheless create a bias against the market economy in the transmission of beliefs, because of the logic of their occupational choice.

In the long run, the bias of intellectuals does not prevent society from learning the true parameters of the economy except in the special case of a zero social entropy. This result could be overturned, though, if a proportion of each new generations had a tendency to "forget", i.e. failed to inherit their parents' beliefs. Societies with different teacher bias would then converge toward permanent differenced in beliefs instead of a mass point at the true parameter values.

A central ingredient for my results is that the intellectual profession - the "teachers" - work in a sector where, once they have entered, they are protected from market forces. However, one should note that not all intellectual professions are in this situation; journalists, writers, artists (who also often intervene in the policy debate) are typically in the exposed sector. Yet the same sort of biases are often observed in those professions.

This shortcoming of the model is clearly a fertile avenue for further research. One possibility is that for some of these professions (journalists), one has inherited negative beliefs relative to average because the profession is more volatile than the market. 


\section{APPENDIX}

Proof of Proposition 2

In this proof and that of Proposition $3, x$ will be equal to $\ln (p /(1-p))$ for a parent, and $x^{\prime}=\ln \left(p^{\prime} /\left(1-p^{\prime}\right)\right)$ is the corresponding variable for his offspring.

Let $f_{t}(p)$ be the distribution of prior beliefs in the population for the generation born at date $t$. For any teacher represented by a subscript $T$, his posterior $q_{T}$ is equal to his prior $p_{T}$, which was drawn from the distribution of priors at date $t-1$, with density $\psi_{t-1}() f_{t-1}()$. Therefore, calling $x=\ln (p /(1-p)), \hat{f}_{t}(x)$ the distribution of $x$ at $t$, and $\hat{\psi}_{t}(x)=\psi_{t}\left(\frac{\mathrm{e}^{x}}{1+\mathrm{e}^{x}}\right)$ the weighting function expressed as a function of $x$, we have that

$$
E_{t}\left(\ln \frac{q_{T}}{1-q_{T}}\right)=E_{t} x_{T}=\int_{-\infty}^{+\infty} x \hat{\psi}_{t-1}(x) \hat{f}_{t-1}(x) \mathrm{d} x .
$$

Furthermore,

$$
E_{t-1}\left(\ln \frac{p}{1-p}\right)=E_{t-1} x=\int_{-\infty}^{+\infty} x \hat{f}_{t-1}(x) \mathrm{d} x
$$

Hence,

$$
\begin{aligned}
E_{t} x_{T}-E_{t-1} x & =\int_{-\infty}^{+\infty} x\left(\hat{\psi}_{t-1}(x)-1\right) \hat{f}_{t-1}(x) \mathrm{d} x \\
& =I_{t-1}
\end{aligned}
$$

Since $\int_{-\infty}^{+\infty} \hat{\psi}_{t-1}(x) \hat{f}_{t-1}(x) \mathrm{d} x=1$, this is also equal to

$$
\begin{aligned}
I_{t-1} & =\int_{-\infty}^{+\infty} x\left(\hat{\psi}_{t-1}(x)-1\right) \hat{f}_{t-1}(x) \mathrm{d} x-E_{t-1}(x) \cdot \int_{-\infty}^{+\infty}\left(\hat{\psi}_{t-1}(x)-1\right) \hat{f}_{t-1}(x) \mathrm{d} x \\
& =\int_{-\infty}^{+\infty}\left(x-E_{t-1} x\right)\left(\hat{\psi}_{t-1}(x)-1\right) \hat{f}_{t-1}(x) \mathrm{d} x .
\end{aligned}
$$

By Schwarz's inequality, it follows that

$$
\begin{aligned}
I_{t-1} & \leq\left[\int_{-\infty}^{+\infty}\left(x-E_{t-1} x\right)^{2} \hat{f}_{t-1}(x) \mathrm{d} x\right]^{1 / 2}\left[\int_{-\infty}^{+\infty}\left(\hat{\psi}_{t-1}(x)-1\right)^{2} \hat{f}_{t-1}(x) \mathrm{d} x\right]^{1 / 2}(9) \\
& \leq \sqrt{\operatorname{Var}_{t-1}(x)} \cdot L
\end{aligned}
$$


where $L$ is any number such that $\int_{-\infty}^{+\infty}\left(\hat{\psi}_{t-1}(x)-1\right)^{2} \hat{f}_{t-1}(x) \mathrm{d} x \leq L^{2}$.

Next, (3) implies that for the children of non teachers, we have

$$
E x^{\prime}=\theta\left(E x_{N T}+k z\left(s_{L}\right)\right)+(1-\theta) E x_{T},
$$

where $E x_{N T}$ is the expectation of $x$ conditional on the parent not being a teacher. For children of teachers, on the other hand,

$$
E x^{\prime}=E x_{T} .
$$

This latter formula reflects the fact that children of non teachers do not inherit a random draw from their parent's exposure to the market. Bringing these two formulas together, we find that

$$
E_{t} x=\theta E_{t-1} x+\theta(1-n) k z\left(s_{L}\right)+(1-\theta) E x_{T} .
$$

Substituting (8) and (9) into (10), we can write

$$
E_{t} x \leq E_{t-1}(x)+(1-\theta) \sqrt{\operatorname{Var}_{t-1}(x)} \cdot L+\theta(1-n) k z\left(s_{L}\right) .
$$

Furthermore, we can compute the variance of $x$ by noting that $x^{\prime}-E x^{\prime}=$ $\theta(x-E x)+\theta\left(X_{k}-k z\left(s_{L}\right)\right)+\theta n k z\left(s_{L}\right)$ for the children of non teachers and $x^{\prime}-E x^{\prime}=\theta(x-E x)-\theta(1-n) k z\left(s_{L}\right)$ for the children of teachers. We then get

$$
\operatorname{Var}_{t}(x)=\theta^{2} \operatorname{Var}_{t-1}(x)+\theta^{2} W,
$$

where

$$
W=\operatorname{Var}\left(X_{k}\right)+n(1-n)\left(k z\left(s_{L}\right)\right)^{2} .
$$

Thus for any $\varepsilon>0$ there exists $t_{0}$ such that for all $t>t_{0}, \operatorname{Var}_{t-1}(x) \leq$ $\frac{\theta^{2}}{1-\theta^{2}} W(1+\varepsilon)$. Assume

$$
L \sqrt{\frac{(1-\theta)}{1+\theta}}<-\frac{k z\left(s_{L}\right)}{\sqrt{W}}
$$


then we can find $\varepsilon$ small enough such that the RHS exceeds the LHS by a factor at least equal to $1+\varepsilon$. This in turn implies that $(1-\theta) \sqrt{\operatorname{Var}_{t-1}(x)} \cdot L+$ $\theta k z\left(s_{L}\right)<-\eta$ for $t$ large enough and some $\eta>0$, so that $E_{t} x<E_{0}-t \eta$ and $\lim _{t \rightarrow+\infty} E_{t} x=-\infty$.

The next step consists in showing that we can find an upper bound for $\int_{-\infty}^{+\infty}\left(\hat{\psi}_{t-1}(x)-1\right)^{2} \hat{f}_{t-1}(x) \mathrm{d} x$ which does not vary with $t$. First, note that for all $p$ and $t \Delta_{\min , t} \leq \Delta\left(p, \omega_{t}\right) \leq \Delta_{\max , t}$, with $\Delta_{\min , t}=\omega_{t}-\left(1-s_{L}\right) \bar{w}$ and $\Delta_{\max , t}=\omega_{t}-\left(1-s_{H}\right) \bar{w}$. By monotonicity, it follows that for all $x, \psi_{\min , t-1} \leq$ $\hat{\psi}_{t-1}(x) \leq \psi_{\max , t-1}$, with

$$
\psi_{\min , t-1}=\phi\left(\Delta_{\min , t-1}\right) / n=\frac{e^{\left(\omega_{t-1}-\left(1-s_{L}\right) \bar{w}\right) / \sigma}}{n\left(1+e^{\left(\omega_{t-1}-\left(1-s_{L}\right) \bar{w}\right) / \sigma}\right)},
$$

and similarly

$$
\psi_{\max , t-1}=\frac{e^{\left(\omega_{t-1}-\left(1-s_{H}\right) \bar{w}\right) / \sigma}}{n\left(1+e^{\left(\omega_{t-1}-\left(1-s_{H}\right) \bar{w}\right) / \sigma}\right)} .
$$

Furthermore, since $\int_{-\infty}^{+\infty} \hat{\psi}_{t-1}(x) \hat{f}_{t-1}(x) \mathrm{d} x=1$, it must be that $\psi_{\min , t-1}<$ $1<\psi_{\max , t-1}$. These inequalities are equivalent to $\frac{\omega_{t-1}-\left(1-s_{L}\right) \bar{w}}{\sigma}<-\ln (1 / n-$ 1) $<\frac{\omega_{t-1}-\left(1-s_{H}\right) \bar{w}}{\sigma}$. Substituting the first one into (12), we get that

$$
\psi_{\max , t-1}<\frac{e^{\left(\left(s_{H}-s_{L}\right) \bar{w}\right) / \sigma}}{1-n+n e^{e^{\left.\left(s_{H}-s_{L}\right) \bar{w}\right) / \sigma}}}=\psi_{\max }^{*} .
$$

Similarly, using the second inequality, we get that

$$
\psi_{\min , t-1}>\frac{1}{n+(1-n) e^{e^{\left(\left(s_{H}-s_{L}\right) \bar{w}\right) / \sigma}}}=\psi_{\min }^{*} .
$$

One can readily check that for $n<1 / 2, \psi_{\max }^{*}-1>1-\psi_{\min }^{*}$. Therefore, $\forall x$, $\left(\hat{\psi}_{t-1}(x)-1\right)^{2} \leq\left(\psi_{\max }^{*}-1\right)^{2}=H(\sigma)$. (A similar bound can be derived using $\psi_{\min }^{*}$ if $\left.n>1 / 2\right)$. Therefore,

$$
\int_{-\infty}^{+\infty}\left(\hat{\psi}_{t-1}(x)-1\right)^{2} \hat{f}_{t-1}(x) \mathrm{d} x \leq H(\sigma) .
$$


Furthermore, we clearly have $H^{\prime}(\sigma)$.

Thus we can just pick $L=\sqrt{H(\sigma)}=\psi_{\max }^{*}-1$. Clearly, given $\sigma(11)$ defines a minimum value of $\theta_{m}(\sigma, k)$ for which it is satisfied, and as the LHS is equal to 0 for $\theta=1, \theta_{m}(\sigma, k)<1$. Furthermore, since $H^{\prime}<0, \theta_{m, 1}^{\prime}(\sigma)<0$ unless $\theta_{m}(\sigma, k)=0$. Since $\lim _{\sigma \rightarrow+\infty} H(\sigma)=0, \theta_{m}(\sigma, k)=0$ for $\sigma$ large enough.

Finally, putting together the fact that if (11) holds then $\lim _{t \rightarrow+\infty} E_{t} x=-\infty$ and that the variance of $x$ is bounded by $\frac{\theta^{2}}{1-\theta^{2}} W(1+\varepsilon)$, we can again apply Chebyshev's inequality and prove that $\lim _{t \rightarrow+\infty} P(p>\varepsilon)=0$. Finally since $\operatorname{Var}\left(X_{k}\right)=k \operatorname{Var}\left(X_{1}\right)$, the RHS is increasing in $k$. Therefore, $\theta_{m, 2}^{\prime}(\sigma)<0$ unless $\theta_{m}(\sigma, k)=0$.

\section{Q.E.D.}

\section{Proof of Proposition 3}

Let $x_{m t}$ the most optimistic teacher's prior at $t$. Observe that the ranking of beliefs among the teachers' offsprings is the same as among their parents and that $x_{m t}^{\prime}=\theta x_{m t}+(1-\theta) E x_{T t} \geq x_{m t}$. Therefore at least $n$ people in generation $t+1$ are such that $x \geq x_{m t}$. Consequently, $x_{m t+1} \geq x_{m t}$.

The sequence $\left\{x_{m t}\right\}$ is nondecreasing. Assume it has a finite limit $\bar{x}$. For any $\varepsilon>0$, for $t$ large enough we have $\bar{x}-\varepsilon \leq x_{m t} \leq \bar{x}$. Since $x_{m t+1} \geq x_{m t}^{\prime}$, it must be that $x_{m t}^{\prime}=\theta x_{m t}+(1-\theta) E x_{T t} \leq \bar{x}$. Hence, $E x_{T t} \leq \frac{\bar{x}-\theta x_{m t}}{1-\theta} \leq \bar{x}+\frac{\theta \varepsilon}{1-\theta}$. Also note that since $E x_{T t}>x_{m t}, \bar{x}-\varepsilon<E x_{T t}$.

For any $\eta>0$, let $h_{t}(\eta)$ be the mass of teachers at $t$ such that $x>\bar{x}+\eta$. Then for $t$ large enough, $E x_{T t} \geq\left(1-\frac{h_{t}}{n}\right)(\bar{x}-\varepsilon)+\frac{h_{t}}{n}(\bar{x}+\eta)$. Since also $E x_{T t} \leq \bar{x}+\frac{\theta \varepsilon}{1-\theta}$, it follows that $h_{t}(\eta) \leq \frac{n \varepsilon}{(1-\theta)(\varepsilon+\eta)}$.

Note also that there exists $A$ such that:

$$
\exists t_{0}, \forall t>t_{0}, \text { for any } B<1, P\left(x_{t}>\bar{x}-A\right)>B \text {. }
$$


This property clearly holds for teachers, and it holds for the whole population if it holds for non teachers. Let us prove it for non teachers. Take any $\psi>0$ and let $A=\varepsilon-\frac{\theta}{1-\theta} k z^{-}+\psi$. Then for $x_{t}>\bar{x}-A, x_{t}^{\prime}>\theta\left(\bar{x}-A+X_{k}\right)+(1-\theta)(\bar{x}-\varepsilon)=$ $\bar{x}-\theta A+\theta X_{k}-(1-\theta) \varepsilon \geq \bar{x}-\theta A+\theta k z^{-}-(1-\theta) \varepsilon=\bar{x}-A+(1-\theta) \psi>\bar{x}-A$. This proves that if an individual's prior exceeds $\bar{x}-A$, so will all his descendents' priors. Furthermore, if $x_{t}<\bar{x}-A, x_{T}^{\prime} \geq \theta\left(x_{t}+X_{k}\right)+(1-\theta)(\bar{x}-\varepsilon) \geq$ $\theta\left(x_{t}+k z^{-}\right)+(1-\theta)\left(\bar{x}-A-\frac{\theta}{1-\theta} k z^{-}+\psi\right)=\theta x_{t}+(1-\theta)(\bar{x}-A+\psi)$. This process eventually exceeds $\bar{x}-A$. Thus by taking $t$ large enough, we can maintain any fraction of the population at a level of $x$ greater than $\bar{x}-A$.

Finally, note that a proportion $s^{k}$ of non-teachers have $X_{k}=k z^{+}$. For such an offspring, $x_{t}^{\prime}=\theta\left(x_{t}+k z^{+}\right)+(1-\theta) E x_{T t} \geq \theta\left(x_{t}+k z^{+}\right)+(1-\theta)(\bar{x}-\varepsilon)$. Therefore, if $x_{t}>\bar{x}-A_{t}$, then $x_{t}^{\prime}>\bar{x}-\theta A_{t}+\theta k z^{+}-(1-\theta) \varepsilon$. Consider the sequence defined by $A_{t}=A$ and $A_{u+1}=\theta A_{u}+(1-\theta) \varepsilon-\theta k z^{+}$for $u>t$. Then there is at least a mass $(B-n) s^{k(u-t)}$ individuals at $u$ such that $x>\bar{x}-A_{u}$. Furthermore, we must have $A_{u}=\theta^{u-t} \alpha_{0}+\alpha_{1}$, where $\alpha_{0}=A+\frac{\theta}{1-\theta} k z^{+}-\varepsilon>0$ et $\alpha_{1}=\varepsilon-\frac{\theta}{1-\theta} k z^{+}<0$ (we can always pick $\varepsilon$ small enough so that these inequalities hold). For $\eta<\frac{\theta}{1-\theta} k z^{+}-\varepsilon$, we have that $A_{u}<-\eta$ for

$$
u-t>\frac{\ln \left(\frac{\theta}{1-\theta} k z^{+}-\varepsilon-\eta\right)-\ln \left(\frac{\theta}{1-\theta} k z^{+}-\varepsilon+A\right)}{\ln \theta} .
$$

Therefore, in this zone, we have at least $(B-n) s^{k(u-t)}$ people such that $x>\bar{x}+\eta$. This means that $h_{u}(\eta) \geq(B-n) s^{k(u-t)}$. At the same time, we already know that $h_{u}(\eta) \leq \frac{n \varepsilon}{(1-\theta)(\varepsilon+\eta)}$. Noting that the lowest possible integer value of $u-t$ which satisfies (13) cannot exceed $\frac{\ln \left(\frac{\theta}{1-\theta} k z^{+}-\varepsilon-\eta\right)-\ln \left(\frac{\theta}{1-\theta} k z^{+}-\varepsilon+A\right)}{\ln \theta}+1$, we see that the following inequality must necessarily hold:

$\ln (B-n)+k \ln s .\left[\frac{\ln \left(\frac{\theta}{1-\theta} k z^{+}-\varepsilon-\eta\right)-\ln \left(\frac{\theta}{1-\theta} k z^{+}-\varepsilon+A\right)}{\ln \theta}+1\right] \leq \ln \frac{n \varepsilon}{(1-\theta)(\varepsilon+\eta)}$. 
Clearly, we can have it violated by picking a low enough value of $\varepsilon$, which allows us to have the RHS arbitrarily negative.

Thus the nondecreasing sequence $x_{m t}$ cannot have a finite limit, implying $\lim x_{m t}=+\infty$. Consequently, $\lim E x_{T t}=+\infty$, and the rest follows by applying (3).

Q.E.D. 


\section{REFERENCES}

Alesina, Alberto \& La Ferrara, Eliana, 2005. "Preferences for redistribution in the land of opportunities," Journal of Public Economics, 89(5-6), 897-931.

Benabou, R. and E.Ok. 2001. "Social Mobility and the Demand for Redistribution: The POUM Hypothesis". Quarterly Journal of Economics, 116(2): $447-487$.

Chamley, Christophe (2000), Rational Herds: Economic Models of Social Learning, Cambridge University Press

Hayek, Friedrich, (1949), "The Intellectuals and Socialism", University of Chicago Law Review

Piketty, Thomas (1995), "Social mobility and redistributive politics" Quarterly Journal of Economics, 110, 3, 551-584

Saint-Paul, Gilles (1993), "On the political economy of labor market flexibility", NBER Macroecnomics Annual

(2000), The Political Economy of Labour Market Institutions, Oxford University Press

(2004), "Why are European countries diverging in their unemployment experience ?", Journal of Economic Perspectives 


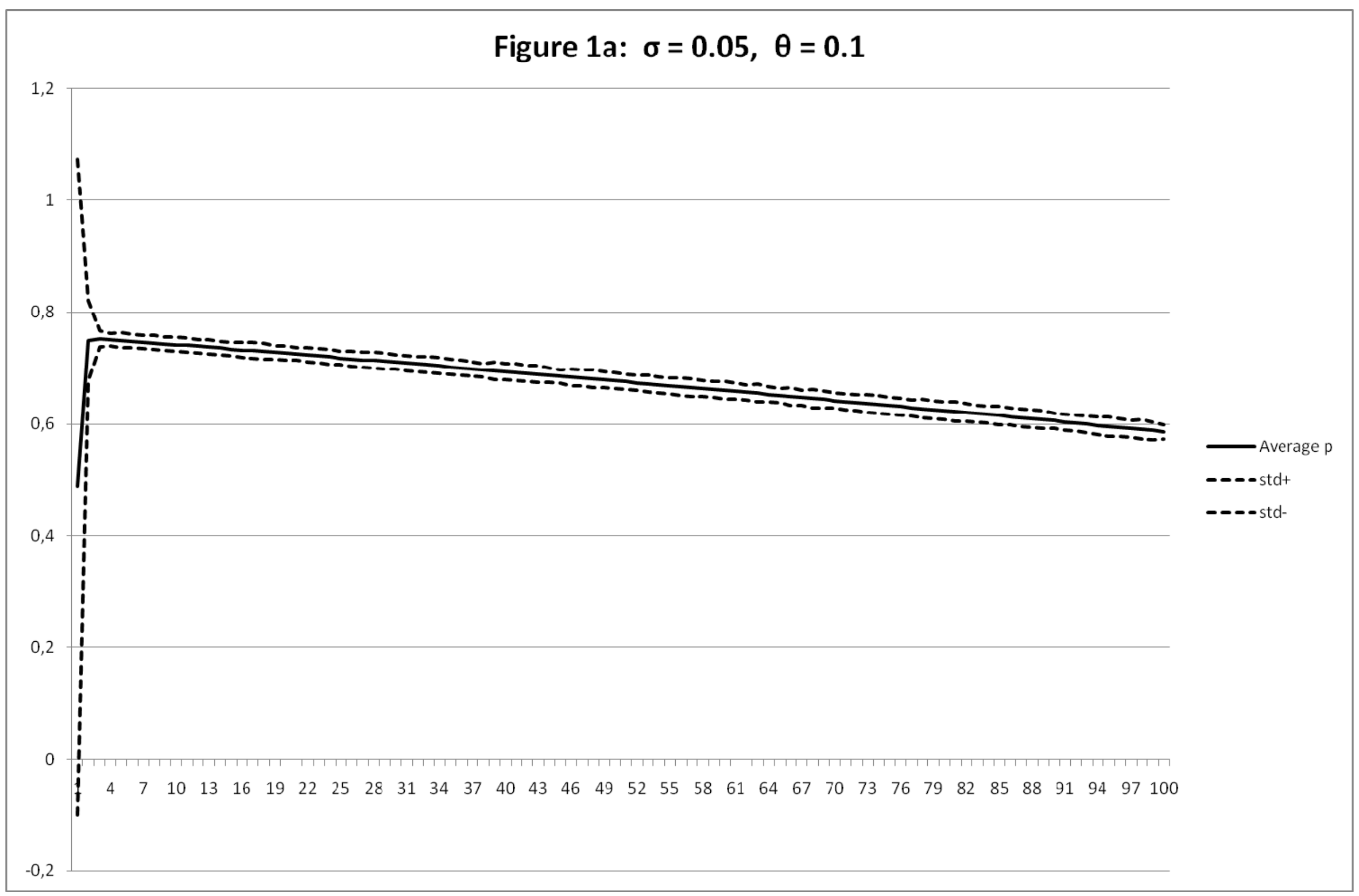




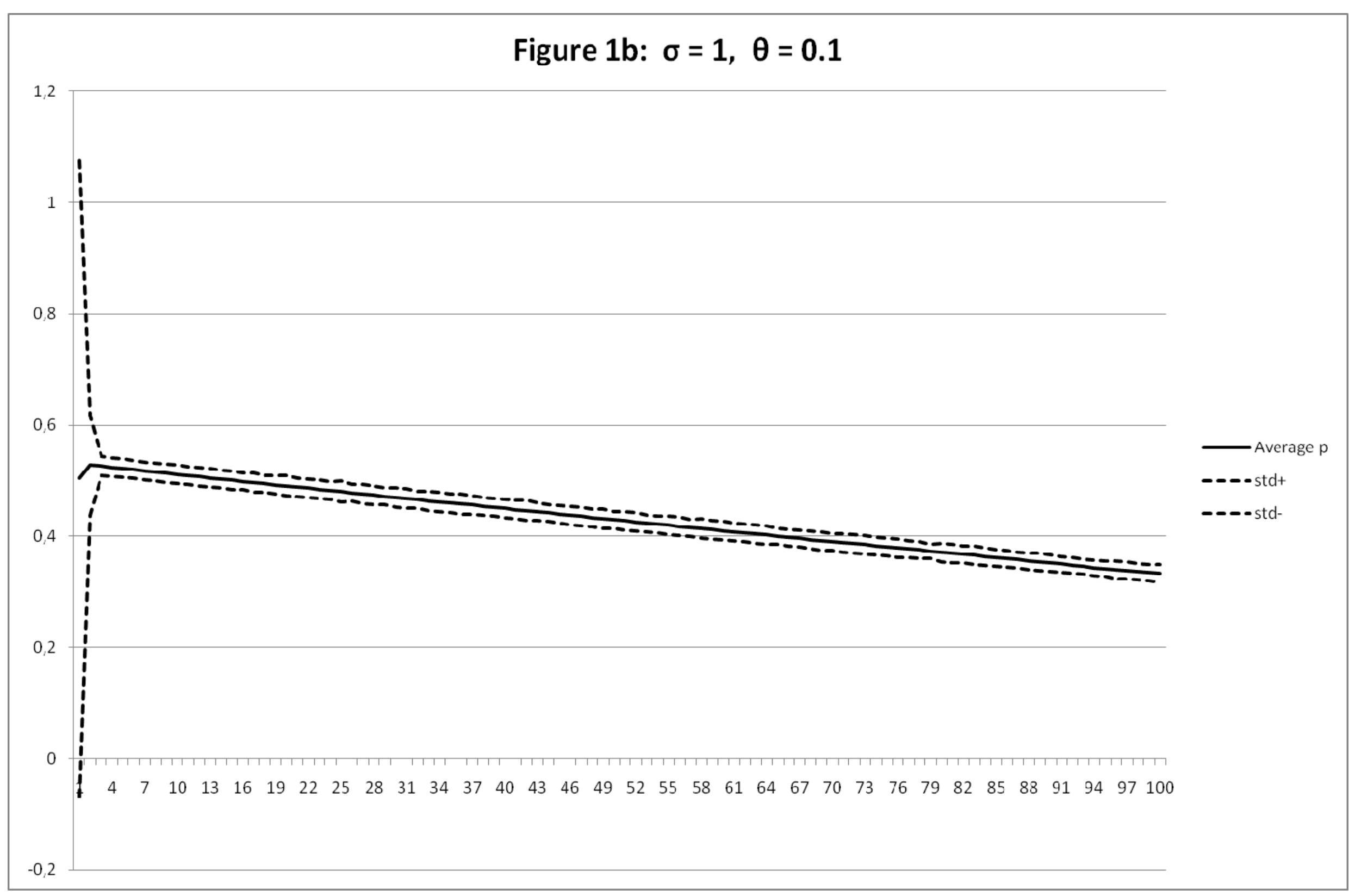




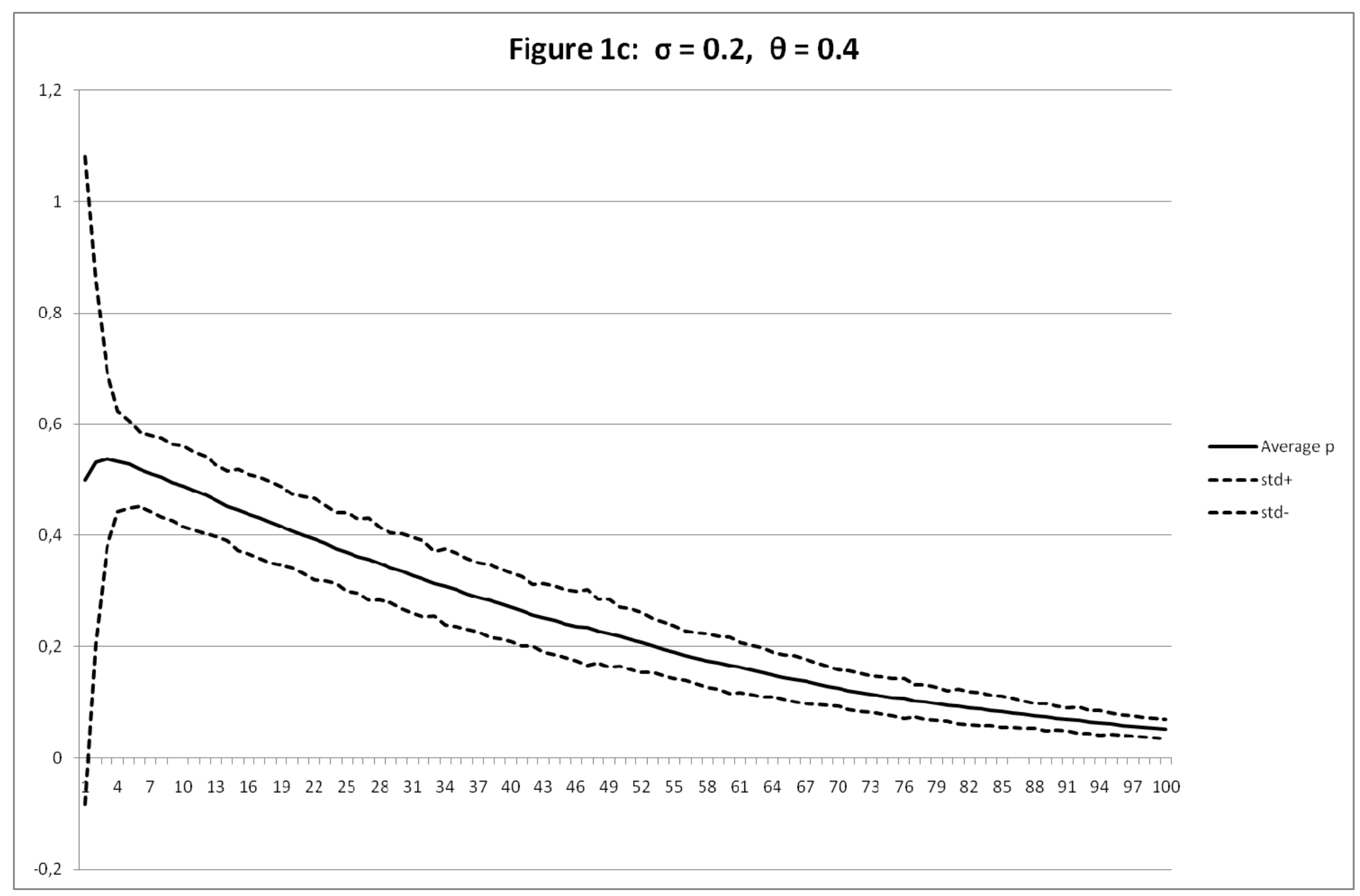




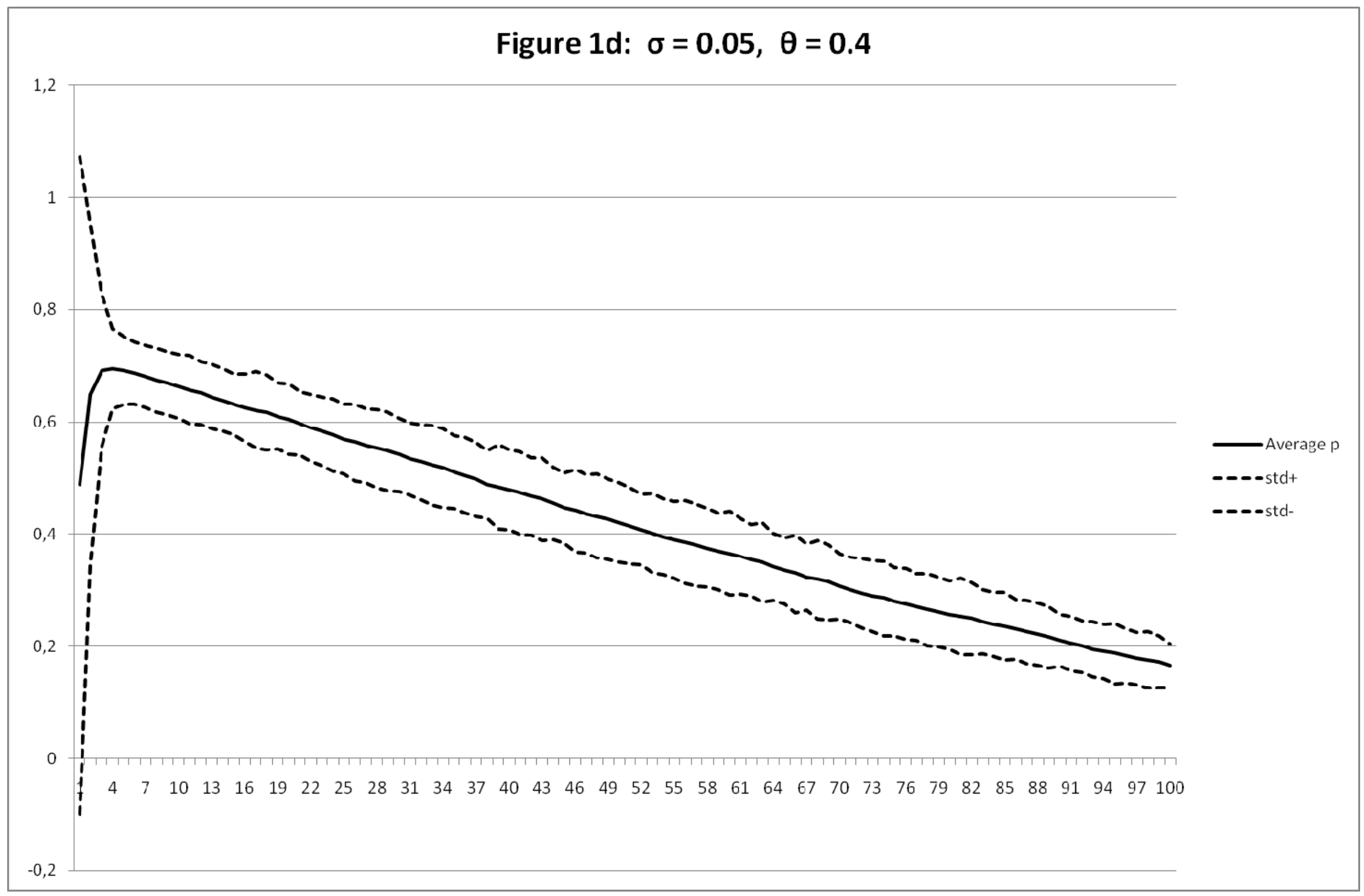




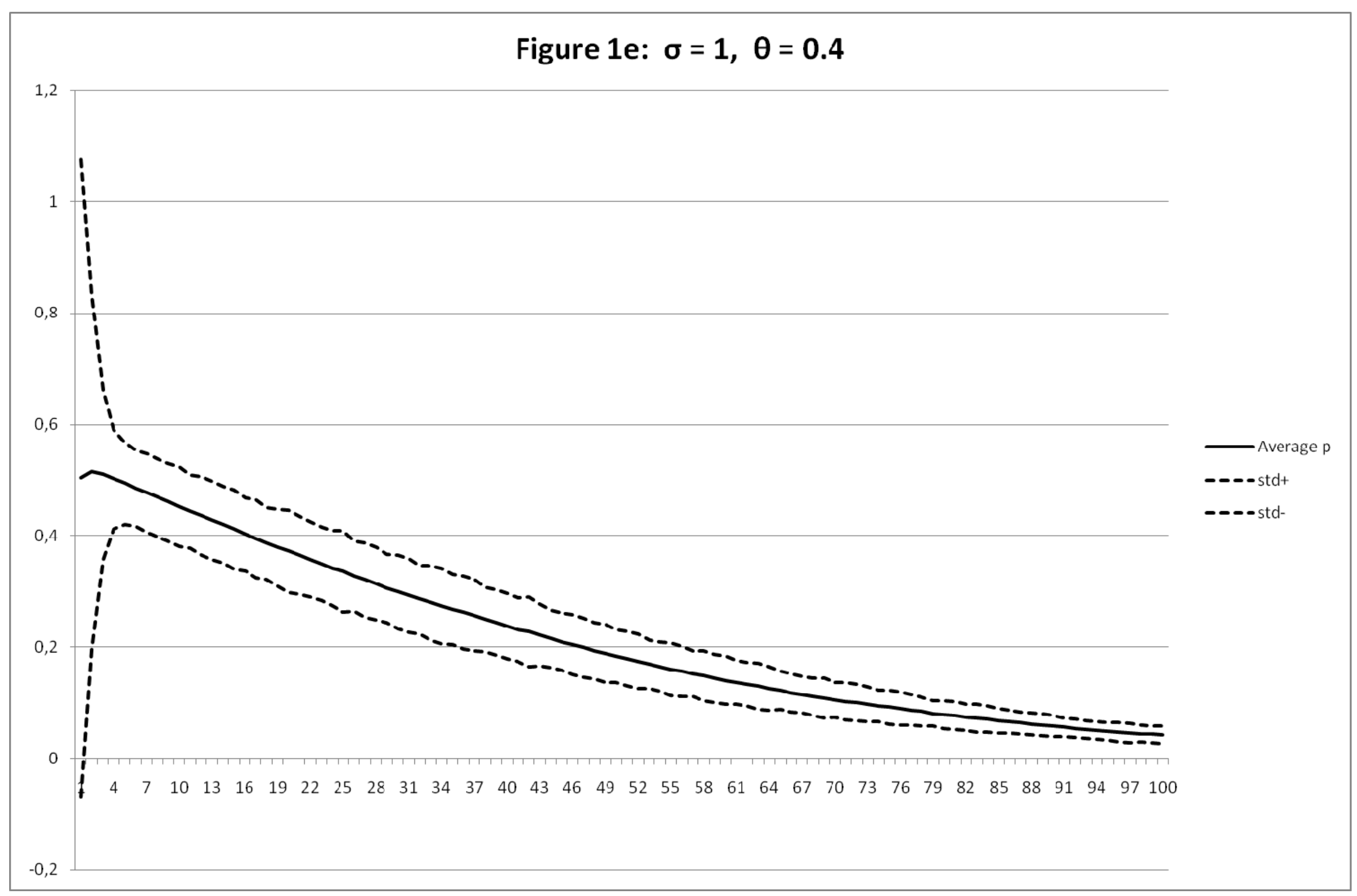




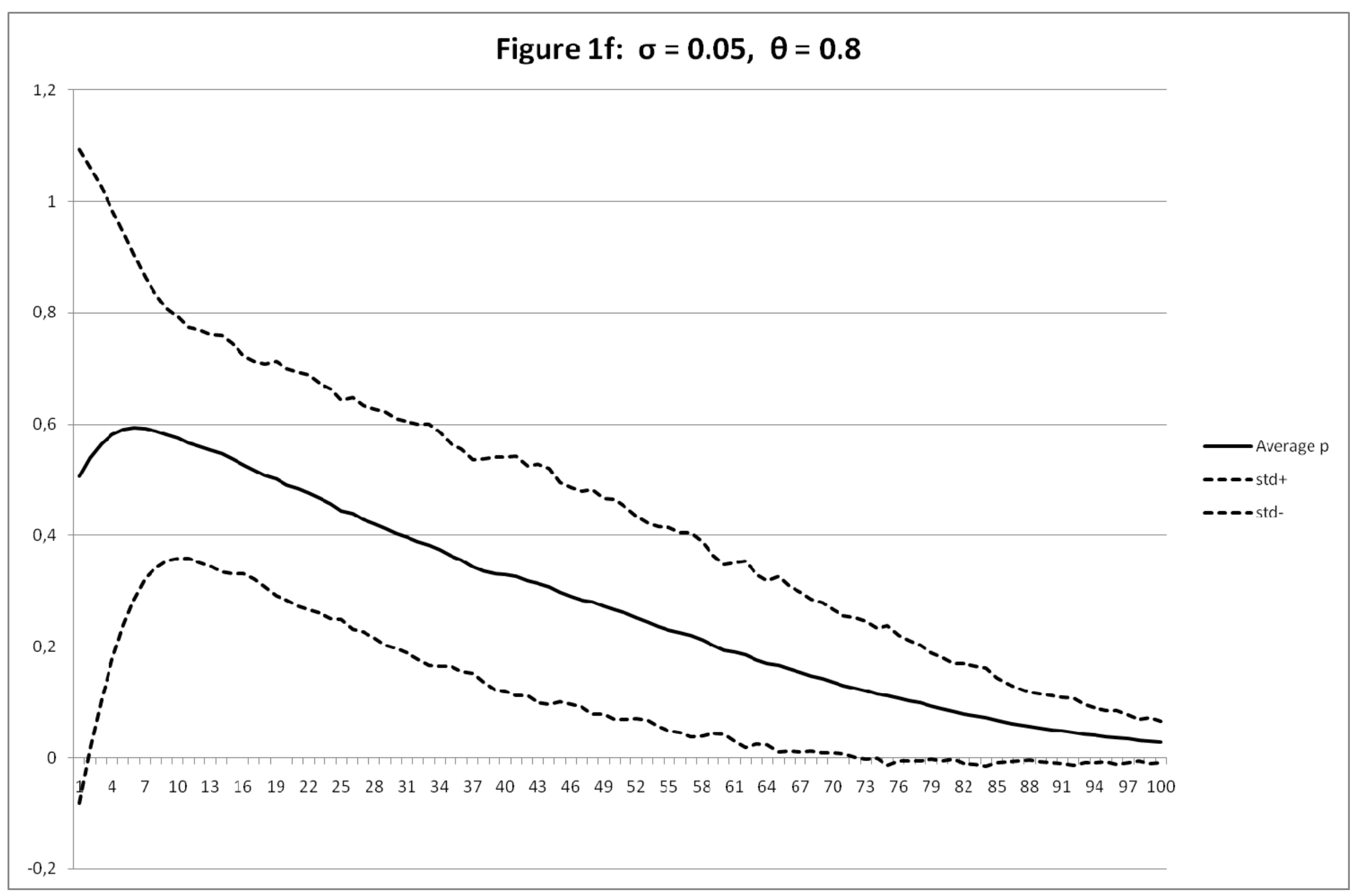




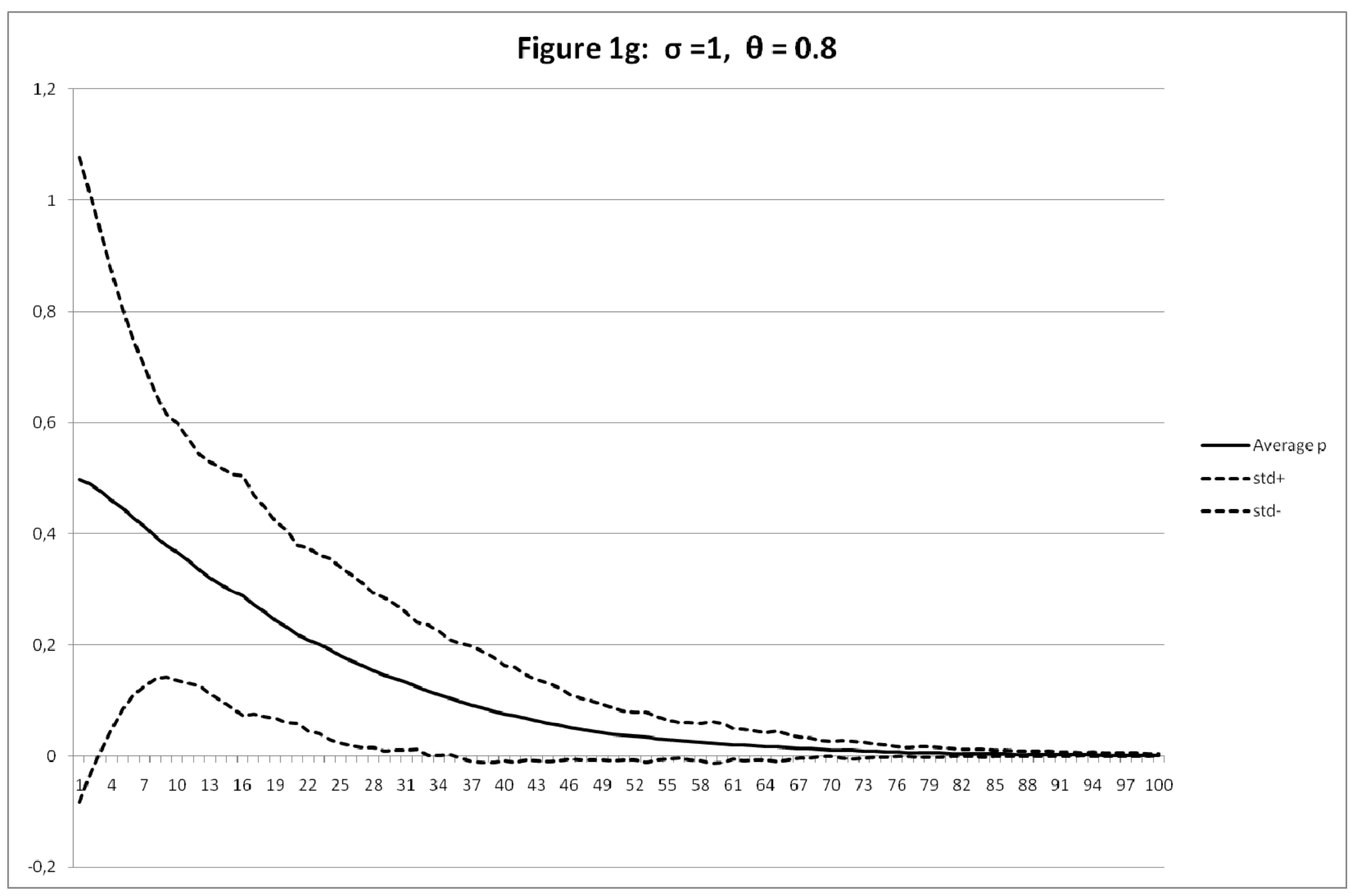




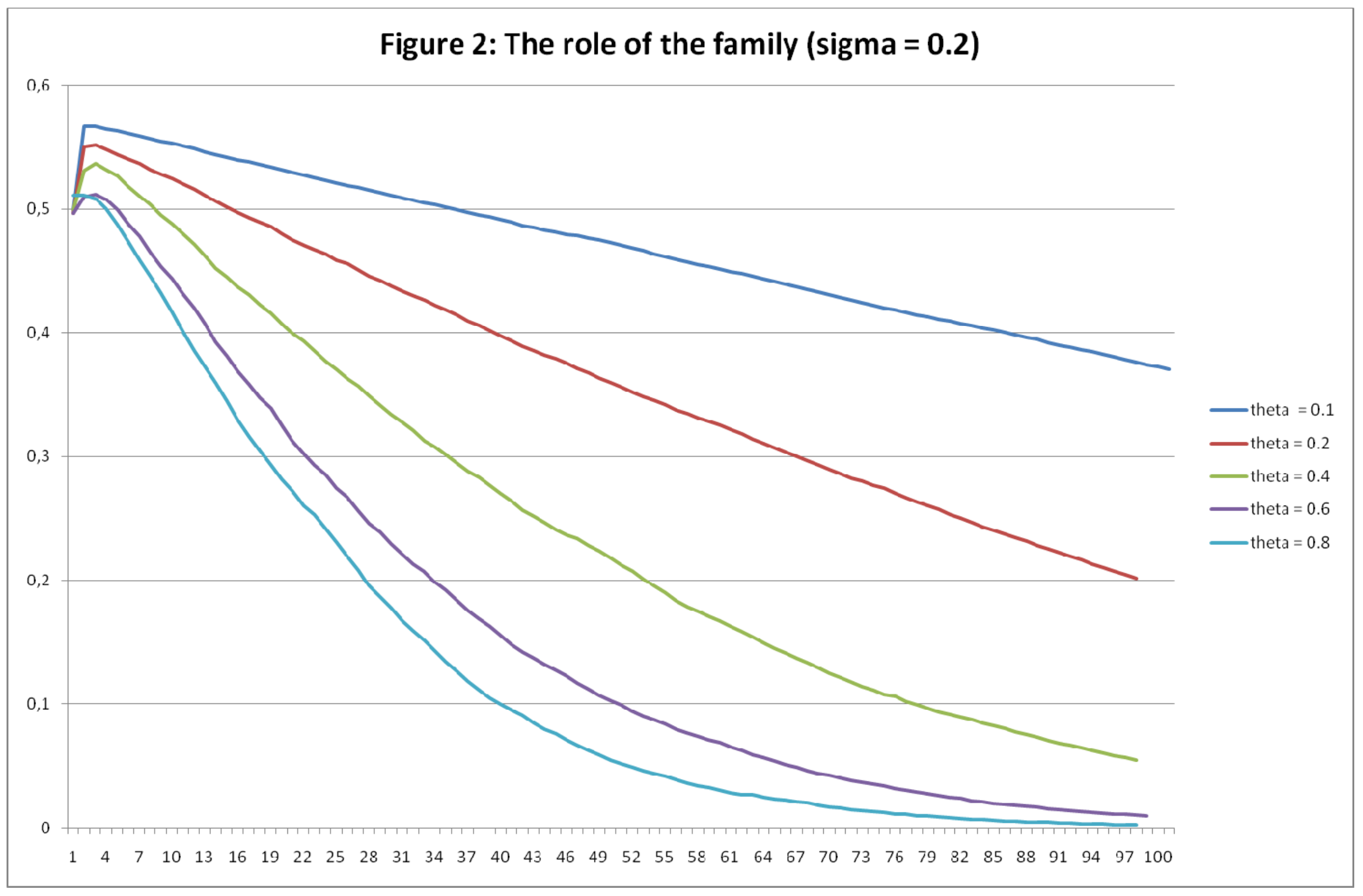




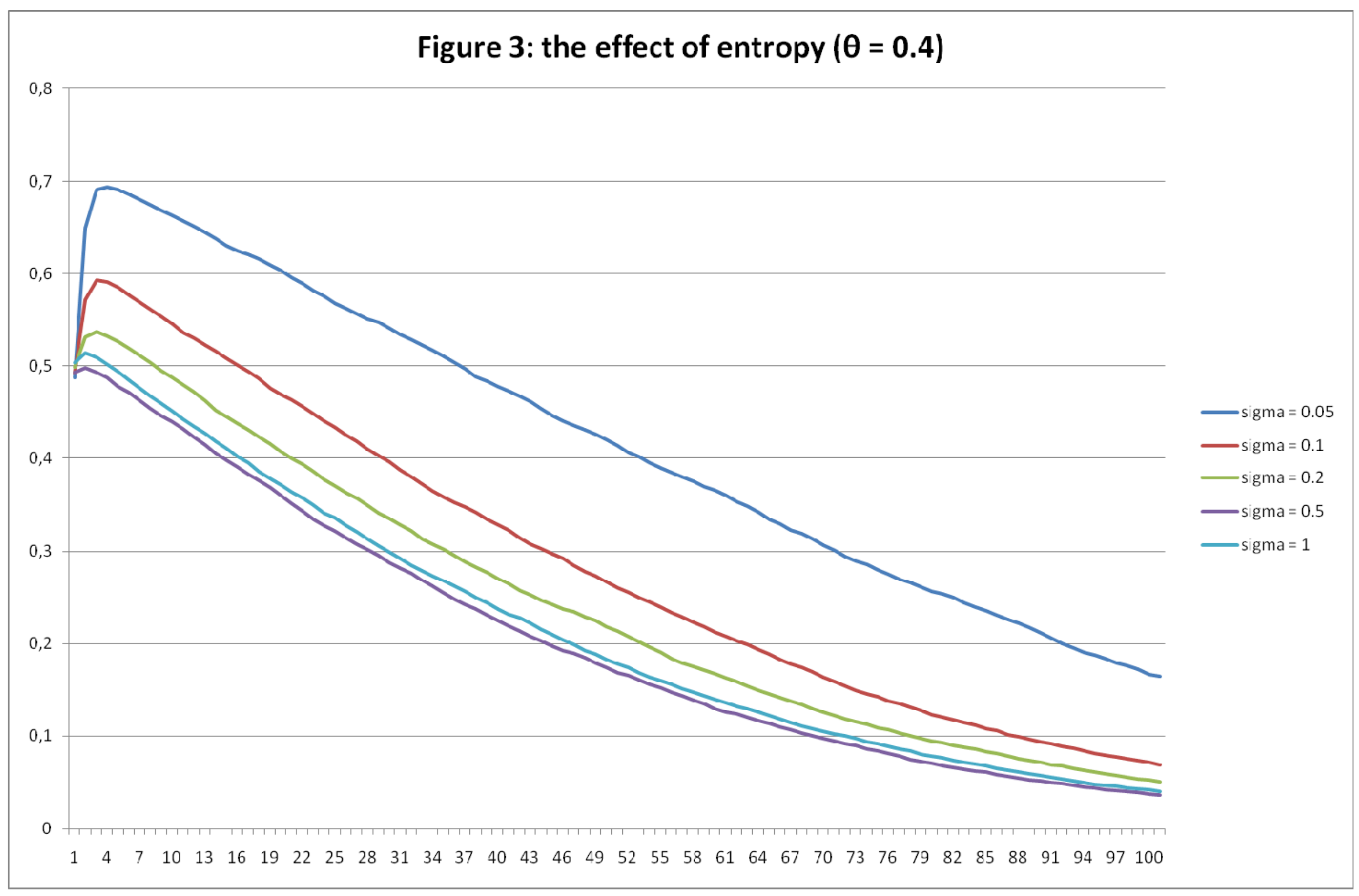


Figure 4: The zero entropy case

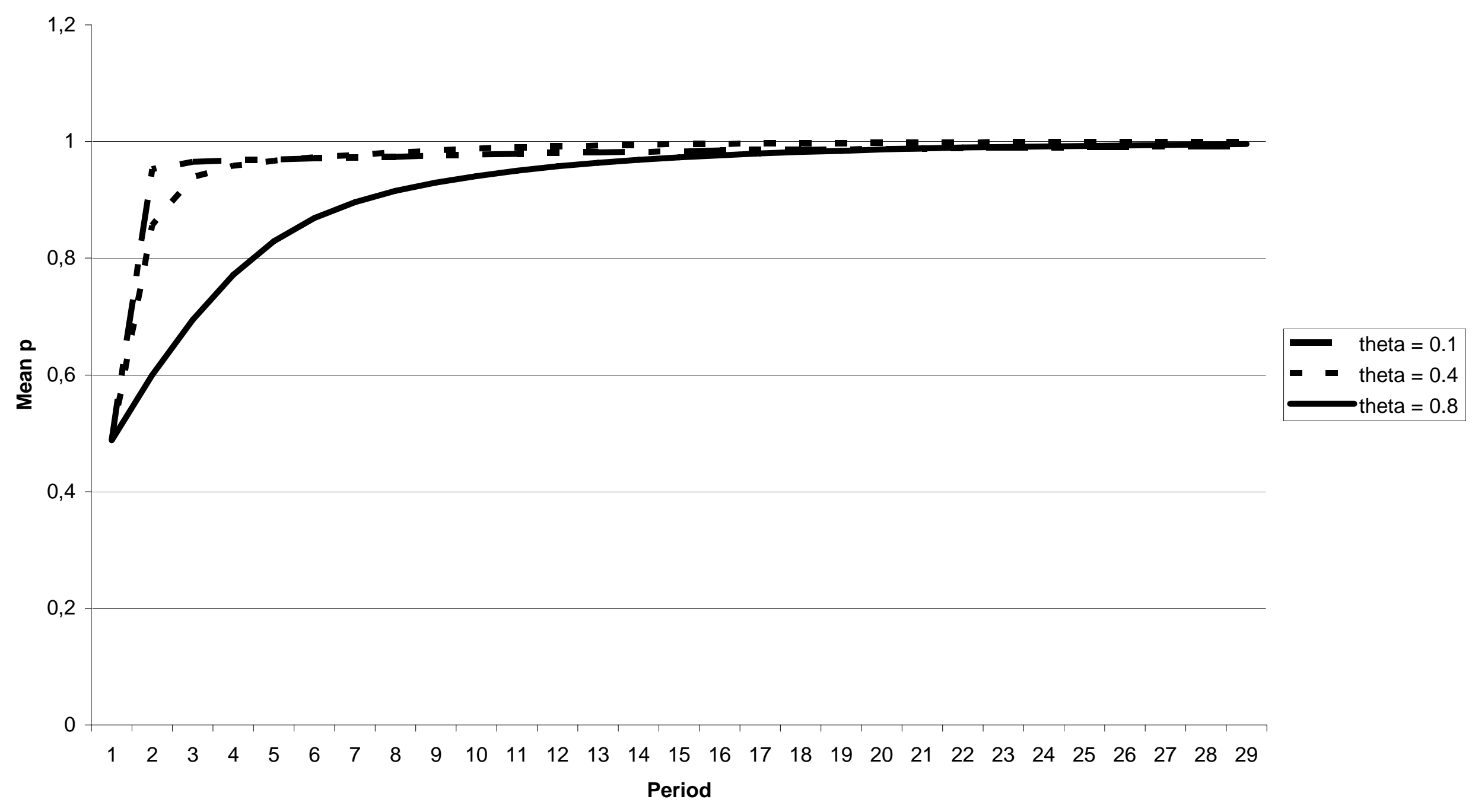


Figure 5: the insulation effect

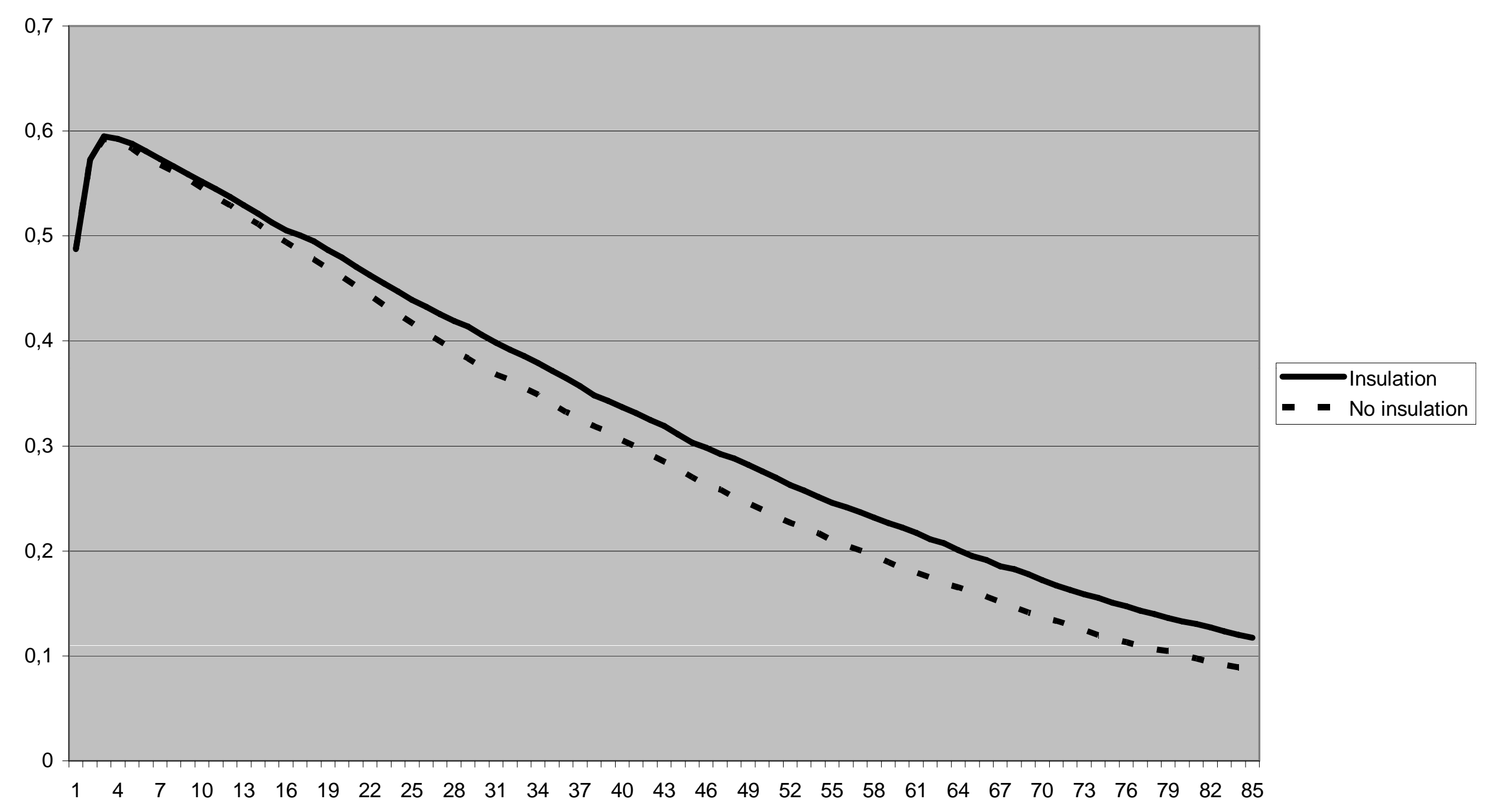




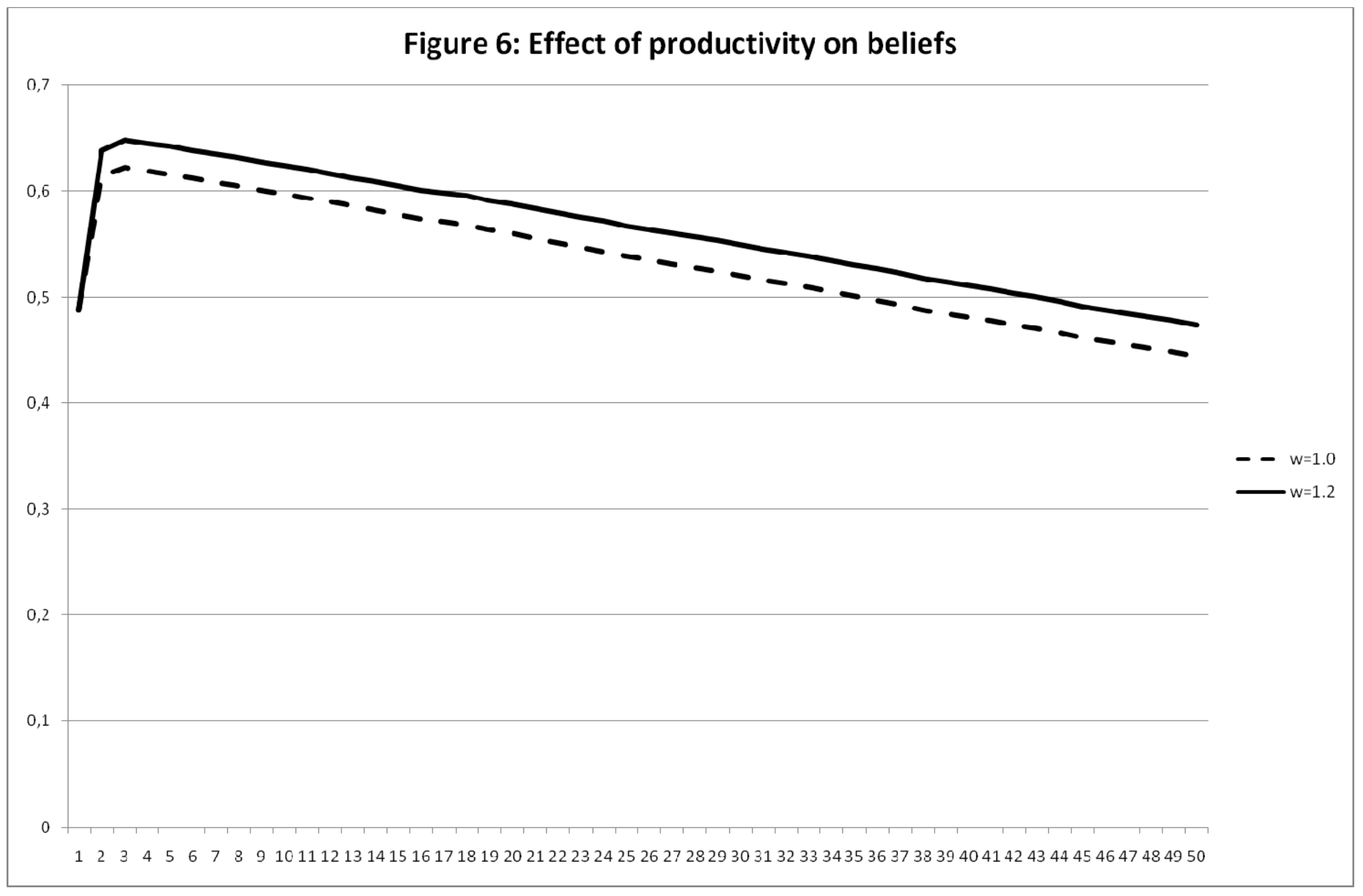




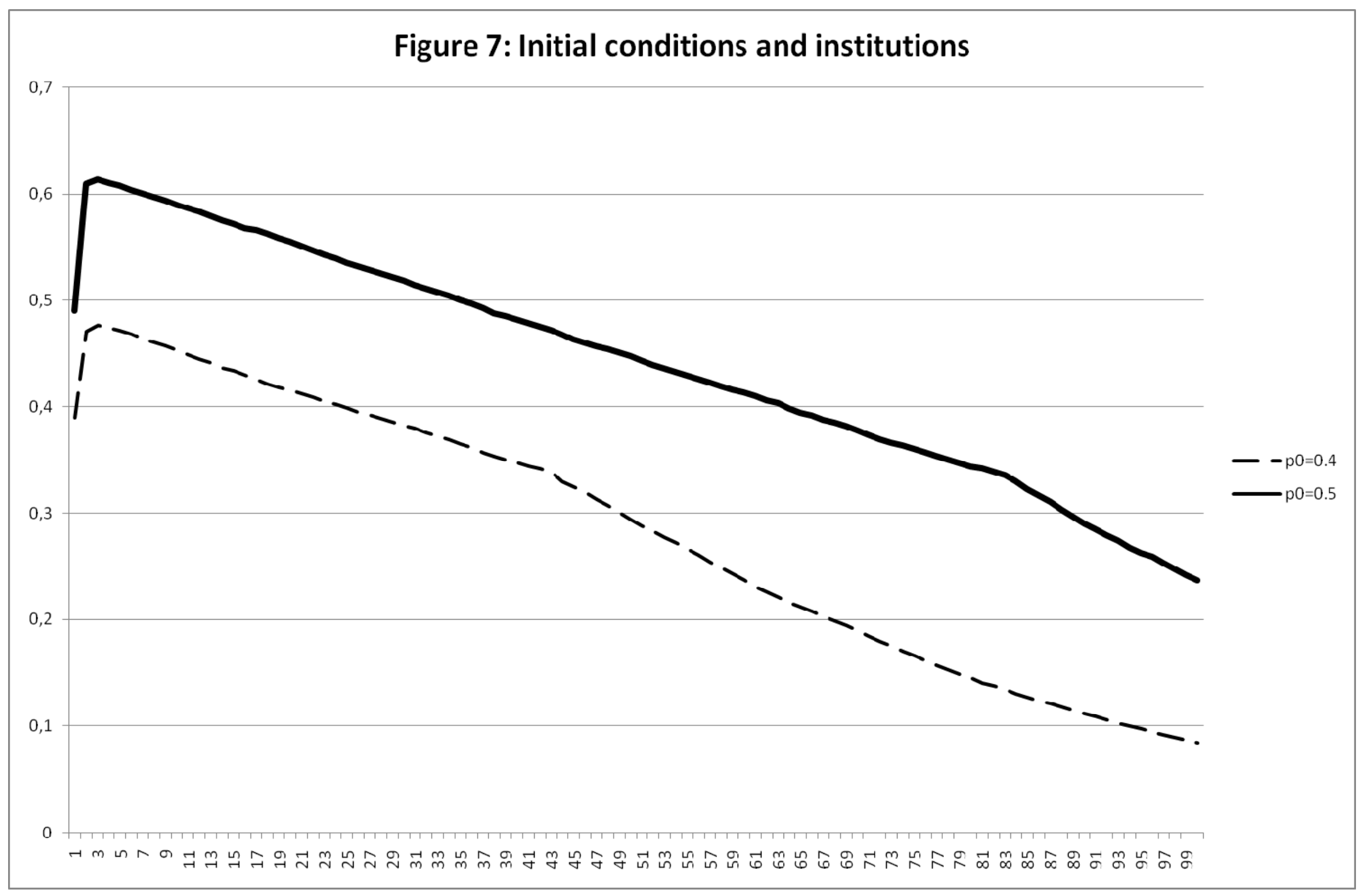




\begin{tabular}{|l|l|l|l|}
\hline Candidate & ideology & $\begin{array}{l}\text { \% among } \\
\text { teachers }\end{array}$ & $\begin{array}{l}\% \text { in total } \\
\text { population }\end{array}$ \\
\hline Arlette Laguiller & $\begin{array}{l}\text { Extreme } \\
\text { Left }\end{array}$ & 8 & 5.7 \\
\hline $\begin{array}{l}\text {-Olivier } \\
\text { Besancenot }\end{array}$ & $\begin{array}{l}\text { Extreme } \\
\text { Left }\end{array}$ & 2 & 4.2 \\
\hline - Robert Hue & $\begin{array}{l}\text { Extreme } \\
\text { Left }\end{array}$ & 3 & 3.4 \\
\hline $\begin{array}{l}\text {-Jean-Pierre } \\
\text { Chevènement }\end{array}$ & Left & 16 & 5.3 \\
\hline - Lionel Jospin & Left & 29 & 16.2 \\
\hline - Noël Mamère & Left & 14 & 5.2 \\
\hline - François Bayrou & Centre & 3 & 6.8 \\
\hline - Jacques Chirac & Right & 23 & 19.9 \\
\hline - Alain Madelin & Right & 2 & 3.9 \\
\hline - Charles pasqua & Right & 0 & -- \\
\hline $\begin{array}{l}\text { - Jean-Marie le } \\
\text { Pen }\end{array}$ & $\begin{array}{l}\text { Extreme } \\
\text { Right }\end{array}$ & 0 & 16.9 \\
\hline - Bruno Mégret & $\begin{array}{l}\text { Extreme } \\
\text { Right }\end{array}$ & 0 & 2.3 \\
\hline
\end{tabular}

Table 1 - French teachers' voting in the 2002 presidential election 
at. The free enterprise system and free market economy is the best system on which to base the future of the world.

\begin{tabular}{|c|c|c|c|c|c|c|c|c|}
\hline & $\begin{array}{r}\text { Total } \\
\text { Agree }\end{array}$ & $\begin{array}{c}\text { Total } \\
\text { Disagree }\end{array}$ & $\begin{array}{c}\text { Strongly } \\
\text { Agree }\end{array}$ & $\begin{array}{c}\text { Somewhat } \\
\text { Agree }\end{array}$ & $\begin{array}{c}\text { Somewhat } \\
\text { Disagree }\end{array}$ & $\begin{array}{l}\text { Strongly } \\
\text { disagree }\end{array}$ & $\begin{array}{l}\text { Depends } \\
\text { / Neither }\end{array}$ & $\begin{array}{c}\text { DK / } \\
\text { Refused }\end{array}$ \\
\hline Argentina & 42 & 29 & 11 & 31 & 13 & 16 & 2 & 26 \\
\hline Brazil & 57 & 30 & 18 & 40 & 19 & 11 & 4 & 9 \\
\hline Canada & 65 & 29 & 22 & 43 & 19 & 10 & 2 & 3 \\
\hline China & 74 & 20 & 25 & 49 & 16 & 4 & 3 & 4 \\
\hline France & 36 & 50 & 10 & 26 & 27 & 23 & 3 & 11 \\
\hline Germany & 65 & 32 & 29 & 36 & 24 & 9 & 2 & 1 \\
\hline Great Britain & 66 & 27 & 26 & 39 & 17 & 10 & 2 & 5 \\
\hline India & 70 & 17 & 34 & 35 & 12 & 6 & 3 & 11 \\
\hline Indonesia & 68 & 29 & 22 & 46 & 25 & 4 & 1 & 3 \\
\hline Italy & 59 & 31 & 21 & 38 & 20 & 12 & 4 & 5 \\
\hline Kenya & 59 & 25 & 33 & 25 & 12 & 13 & 3 & 13 \\
\hline Mexico & 61 & 38 & 21 & 40 & 27 & 11 & $\mathrm{O}$ & 1 \\
\hline Nigeria & 66 & 29 & 34 & 31 & 13 & 16 & 2 & 4 \\
\hline Philippines & 73 & 22 & 23 & 50 & 17 & 5 & 2 & 4 \\
\hline Poland & 63 & 19 & 22 & 41 & 14 & 5 & 4 & 14 \\
\hline Russia & 43 & 34 & 11 & 32 & 25 & 9 & 7 & 15 \\
\hline S. Korea & 70 & 19 & 11 & 60 & 17 & 2 & 5 & 6 \\
\hline Spain & 63 & 28 & 27 & 36 & 14 & 14 & 1 & 8 \\
\hline Turkey & 47 & 36 & 5 & 42 & 31 & 6 & 4 & 12 \\
\hline USA & 71 & 24 & 34 & 37 & 15 & 9 & 2 & 3 \\
\hline Average & 61 & 28 & 22 & 39 & 19 & 10 & 3 & 8 \\
\hline
\end{tabular}

Table 2 - Beliefs about the working of free markets 